\title{
Curcumin Enhanced Busulfan-Induced Apoptosis through Downregulating the Expression of Survivin in Leukemia Stem-Like KG1a Cells
}

\author{
Guangyang Weng, ${ }^{1}$ Yingjian Zeng, ${ }^{2}$ Jingya Huang, ${ }^{3}$ Jiaxin Fan, ${ }^{2}$ and Kunyuan Guo ${ }^{1}$ \\ ${ }^{1}$ Department of Hematology, Zhujiang Hospital, Southern Medical University, Guangzhou 510000, China \\ ${ }^{2}$ Department of Hematology, Jiangmen Wuyi Traditional Chinese Medicine Hospital, Jiangmen 529000, China \\ ${ }^{3}$ Department of hemodialysis, Shenzhen Traditional Chinese Medicine Hospital, Shenzhen 518000, China
}

Correspondence should be addressed to Kunyuan Guo; wodeyoujian@foxmail.com

Received 28 February 2015; Accepted 24 April 2015

Academic Editor: Pratheeshkumar Poyil

Copyright (C) 2015 Guangyang Weng et al. This is an open access article distributed under the Creative Commons Attribution License, which permits unrestricted use, distribution, and reproduction in any medium, provided the original work is properly cited.

\begin{abstract}
Leukemia relapse and nonrecurrence mortality (NRM) due to leukemia stem cells (LSCs) represent major problems following hematopoietic stem cell transplantation (HSCT). To eliminate LSCs, the sensitivity of LSCs to chemotherapeutic agents used in conditioning regimens should be enhanced. Curcumin (CUR) has received considerable attention as a result of its anticancer activity in leukemia and solid tumors. In this study, we investigated the cytotoxic effects and underlying mechanisms in leukemia stem-like KGla cells exposed to busulfan (BUS) and CUR, either alone or in combination. KGla cells exhibiting BUS-resistance demonstrated by MTT and annexin V/propidium iodide (PI) assays, compared with HL-60 cells. CUR induced cell growth inhibition and apoptosis in KGla cells. Apoptosis of KGla cells was significantly enhanced by treatment with CUR+BUS, compared with either agent alone. CUR synergistically enhanced the cytotoxic effect of BUS. Seven apoptosis-related proteins were modulated in CURand CUR+BUS-treated cells analyzed by proteins array analysis. Importantly, the antiapoptosis protein survivin was significantly downregulated, especially in combination group. Suppression of survivin with specific inhibitor YM155 significantly increased the susceptibility of KGla cells to BUS. These results demonstrated that CUR could increase the sensitivity of leukemia stem-like KGla cells to BUS by downregulating the expression of survivin.
\end{abstract}

\section{Introduction}

Hematopoietic stem cell transplantation (HSCT) is currently one of the most effective methods of curing hematopoietic malignances [1-3]. In 1977, Thomas reported long-term survival in 13 patients with leukemia who underwent HSCT [4]. However, leukemic patients who received allo-HSCT are still susceptible to relapse and to nonrecurrence mortality (NRM) associated with the toxicity of the chemotherapeutic agents used for conditioning $[5,6]$, such as busulfan (BUS), cytoxan, and etoposide. Leukemia stem cells (LSCs) are considered to be responsible for leukemia relapse and drug resistance $[7,8]$. Complete elimination of LSCs and reduced doses of chemotherapeutic agents are thus essential strategies for improving the prognosis in these patients [9]. Lapidot et al. demonstrated that acute myeloid LSCs possessed the cell phenotype of $\mathrm{CD} 34^{+} \mathrm{CD} 38^{-}$[10]. Notably, KGla cells with a similar phenotype have demonstrated self-renewal potential and chemotherapy and immunotherapy resistance [11, 12]. KGla cells are thus considered as leukemia stem-like cells and provide an ideal cells model for studying LSCs.

The alkylating agent BUS is commonly applied in different conditioning regimens for HSCT, to eliminate the underlying leukemia cells and exert an immunosuppressive effect. However, BUS is associated with severe toxicities, including liver, lung, and skin toxicities, hemorrhagic cystitis, diarrhea, and mucositis [13, 14]. The ability of BUS to inhibit or effectively kill LSCs also remains unclear, leaving the potential for leukemia relapse after HSCT.

Curcumin (CUR) is a polyphenol derived from the rhizomes of turmeric, which has received considerable attention as a result of its chemopreventive, chemotherapeutic, and 
chemosensitizing activities in leukemia and various solid tumors, via targeting multiple signaling pathways [15-19]. CUR thus represents a potential sensitizing agent when combined with chemotherapeutic drugs for treating LSCs.

In this study, we explored the cytotoxic efficiencies and molecular mechanisms of CUR and BUS alone and in combination in KGla cells.

\section{Materials and Methods}

2.1. Reagents. Reagents include RPMI-1640 (Hyclone, SH30809.01B), fetal bovine serum (Hyclone, SH30084.03), penicillin and streptomycin (PAA, P11-010), CUR (Sigma, 458-37-7), DMSO (Amresco, 67-68-5), BUS (Sigma, 5598-1), 3-(4,5-dimethylthiazol-2-yl)-2,5-diphenyltetrazolium bromide (Seebio, 298-93-1), hydroxypropyl methylcellulose (Amresco, 9004-65-3), anti-CD34-PE/CD38-FITC (BD Biosciences, USA), FITC Annexin V Apoptosis Detection Kit I (BD Biosciences, USA), CycleTEST Plus DNA Kit (BD Biosciences, USA), anti-PARP (BD, USA, 1:500), anti-caspase-3 (CST, USA, 1:5000), anti-survivin (BD, USA, 1:5000), ym155 (SELLECK, 781661-94-7), Human Apoptosis Antibody Array Kit (RayBio, USA), electrophoresis apparatus trophoresis (Tanon EPS200), and LI-COR Odyssey Scanner (USA).

2.2. Cell Lines and Culture. Human acute myeloid leukemia KGla cells and human acute promyelocyte leukemia HL-60 cells were cultured in RPMI-1640 with $10 \%$ inactivated fetal bovine serum, penicillin, and streptomycin at $37^{\circ} \mathrm{C}$ under $5 \% \mathrm{CO}_{2}$, which were kindly presented by Miaorong She (Department of Hematology, Guangdong General Hospital, Guangzhou, China).

2.3. Cell Viability Assay. Cells viability was estimated by MTT assay. KGla and HL-60 cells in logarithmic phase at $5 \times 10^{5}$ cells/mL were incubated in 96-well plates in the presence or absence of the indicated test samples in a final volume of $0.2 \mathrm{~mL}$ for $24 \mathrm{~h}$ or $48 \mathrm{~h}$ at $37^{\circ} \mathrm{C}$ under $5 \% \mathrm{CO}_{2} .20 \mu \mathrm{L}$ MTT solution ( $5 \mathrm{mg} / \mathrm{mL}$ in phosphate-buffered saline (PBS)) was then added to each well and incubated for $4 \mathrm{~h}$ at $37^{\circ} \mathrm{C}$, followed by the addition of $200 \mu \mathrm{L}$ DMSO. Finally the plates were shaken and examined at $490 \mathrm{~nm}$ using a microplate reader (MK3, Shanghai). Each assay was performed in triplicate. Cells viability was calculated as follows: survival ratio $(\%)=(\mathrm{OD}$ value of experimental samples/OD value of control samples) $\times 100 \%$.

\subsection{Flow Cytometry Analysis for Immunophenotyping.} Single-cell suspensions of $1.0 \times 10^{6}$ of KGla and HL-60 cells were washed in PBS containing $2 \%$ fetal calf serum (FCS). The cells were resuspended in PBS and incubated for $30 \mathrm{~min}$ at $4^{\circ} \mathrm{C}$ with antibodies to surface antigens CD34 and CD38. Mouse IgG isotype was used as a control. The cells were then analyzed by flow cytometry.

2.5. Methylcellulose Colony Formation Test. Approximately 500 treated or untreated cells per well were cultured in RPMI
1640 medium supplemented with $0.9 \%$ methylcellulose and $20 \%$ fetal bovine serum (FBS) in a final volume of $1 \mathrm{~mL}$ at $37^{\circ} \mathrm{C}$ under $5 \% \mathrm{CO}_{2}$. Colonies (>50 cells) were counted and photographs were taken under a light microscopy after 14 days. All the samples were analyzed in triplicate.

2.6. Measurements of Apoptosis. The apoptotic rates of KGla and HL-60 cells were determined by annexin V binding assays, according the manufacturer's instructions. Briefly, approximately $1.0 \times 10^{6}$ cells in 6-well plates were treated with various concentrations of the indicated test samples at $37^{\circ} \mathrm{C}$ under $5 \% \mathrm{CO}_{2}$ for $48 \mathrm{~h}$. The cells were then harvested to analyze apoptosis. Cells were washed twice with cold PBS and then resuspended in $1 \mathrm{x}$ Binding Buffer at a concentration of $1 \times 10^{6}$ cells $/ \mathrm{mL}$ and $100 \mu \mathrm{L}$ of the solution $\left(1 \times 10^{5}\right.$ cells) was transferred to a $5 \mathrm{~mL}$ culture tube and then $5 \mu \mathrm{L}$ of FITC annexin V and $5 \mu \mathrm{L}$ PI were added and the cells were gently vortexed, followed by incubation for $15 \mathrm{~min}$ at room temperature $\left(25^{\circ} \mathrm{C}\right)$ in the dark. Finally, $400 \mu \mathrm{L}$ of $1 \mathrm{x}$ Binding Buffer was added to each tube and the cells were then analyzed by flow cytometry.

2.7. Cell Cycle Analysis. Approximately $1.0 \times 10^{6}$ cells in 6well plates were treated with various concentrations of the indicated test samples at $37^{\circ} \mathrm{C}$ under $5 \% \mathrm{CO}_{2}$ for $48 \mathrm{~h}$. Cell cycle analysis was performed by flow cytometry using the CycleTEST Plus DNA Kit (BD Biosciences), according to manufacture's instructions.

2.8. Western Blot Analysis. Total cellular proteins were isolated with lysis buffer (RIPA). Equal amounts of protein were subjected to $10 \%$ or $15 \%$ polyacrylamide gel electrophoresis and transferred to polyvinylidene difluoride (PVDF) membranes. After blocking with 5\% skim milk, the membranes were incubated with primary antibodies (anti-PARP, anti-caspase-3, and anti-survivin) over night at $4^{\circ} \mathrm{C}$ and then incubated with horseradish peroxidase-conjugated antimouse secondary antibody at room temperature for $1-2 \mathrm{~h}$. The protein bands were imaged using a chemiluminescence reagent (CTB, USA) and densities value of the bands was analyzed using Image J software, with glyceraldehyde 3phosphate dehydrogenase (GAPDH; HC301; 1:5000) as the internal reference.

2.9. Analysis of Apoptosis-Related Proteins by RayBio Arrays. The expression of 43 apoptosis-related proteins was analyzed using a Human Apoptosis Antibody Array Kit (RayBio, USA). Briefly, according to instructions, each of the capture antibodies was printed on the membranes, followed by addition of the treated or untreated cell lysate. After extensive washing, the membranes were incubated with a cocktail of biotin-conjugated anti-apoptotic protein antibodies. After incubation with the infrared fluorescent agent-streptavidin, the fluorescence signals were visualized using a LI-COR Odyssey Scanner.

2.10. Statistical Analysis. The data ware represented as the mean \pm standard deviation (SD) and analyzed using SPSS 

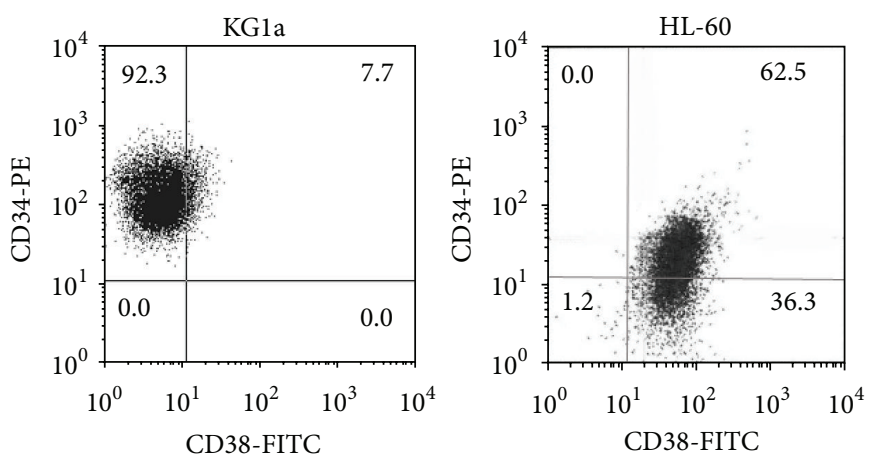

(a)

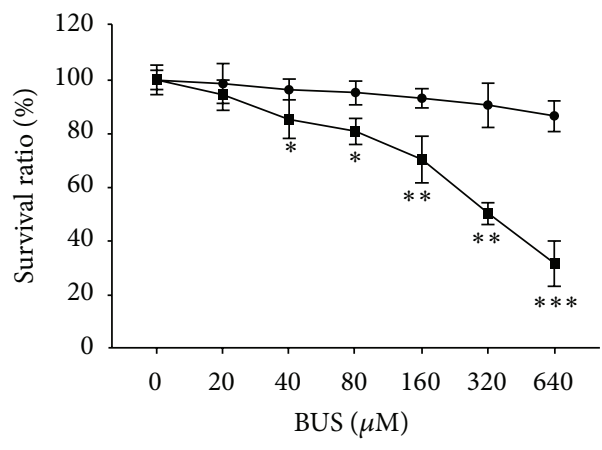

$\mathrm{KG1a} \mathrm{IC}_{50}=22523.1 \mu \mathrm{M}$

HL-60 IC $_{50}=354.5 \mu \mathrm{M}$

(b)

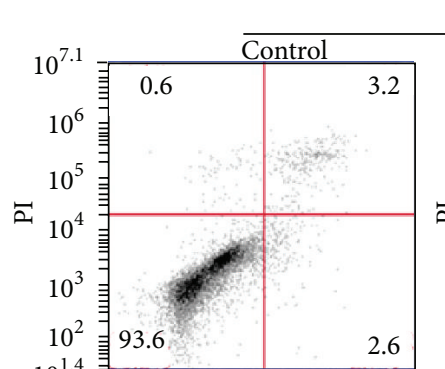

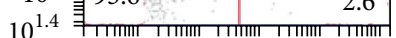
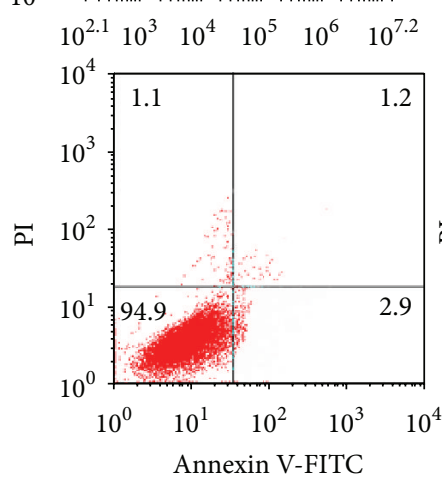

Annexin V-FITC

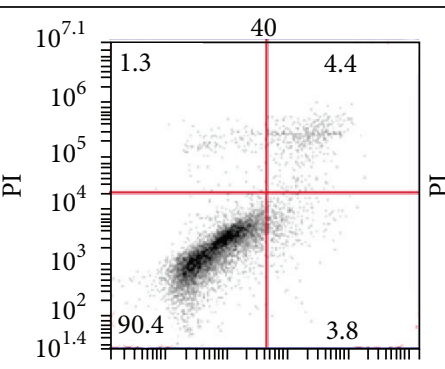

$\operatorname{BUS}(\mu \mathrm{M})$
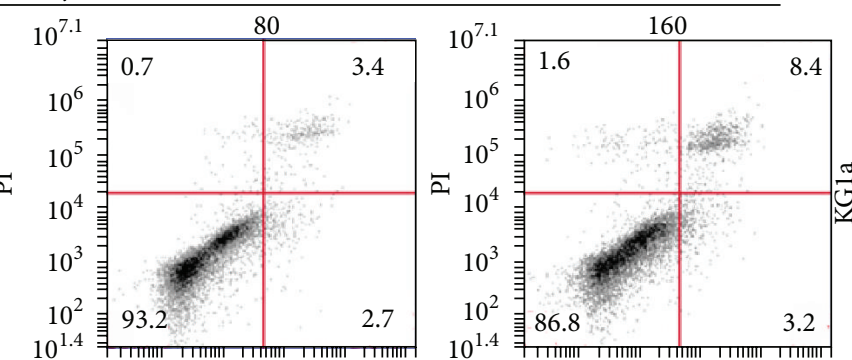

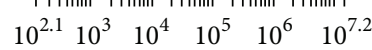
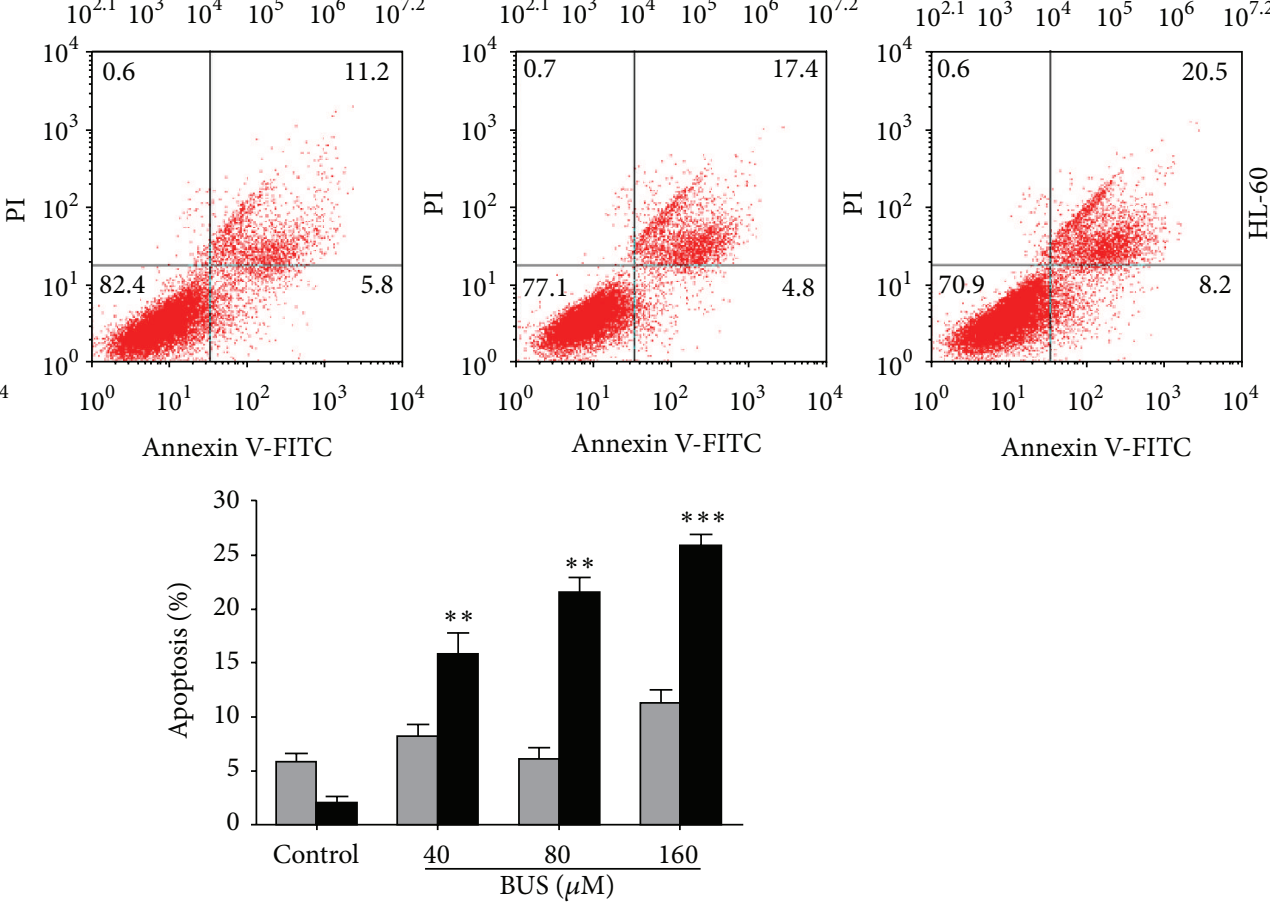

KG1a

HL-60

(c)

FIGURE 1: CD $34^{+} \mathrm{CD} 38^{-}$KGla cells were insensitive to BUS. (a) KGla cells were stained with FITC-conjugated CD38 antibody and PEconjugated CD34 antibody and subjected to flow cytometry to analyze the purity of the CD $34^{+} \mathrm{CD} 38^{-}$cells population. (b, c) KGla cells were exposed to different concentrations of BUS for 24 or $48 \mathrm{~h}$ (c). MTT assay was performed (b) and apoptosis (c) was detected by annexin V/PI assay. Cells in the lower right quadrant represent early apoptosis and cells in the upper right quadrant represent late apoptosis. The graph displays the means \pm SD of three independent experiments. ${ }^{* *} P<0.01,{ }^{* * *} P<0.001$ (compared with untreated KGla cells). 


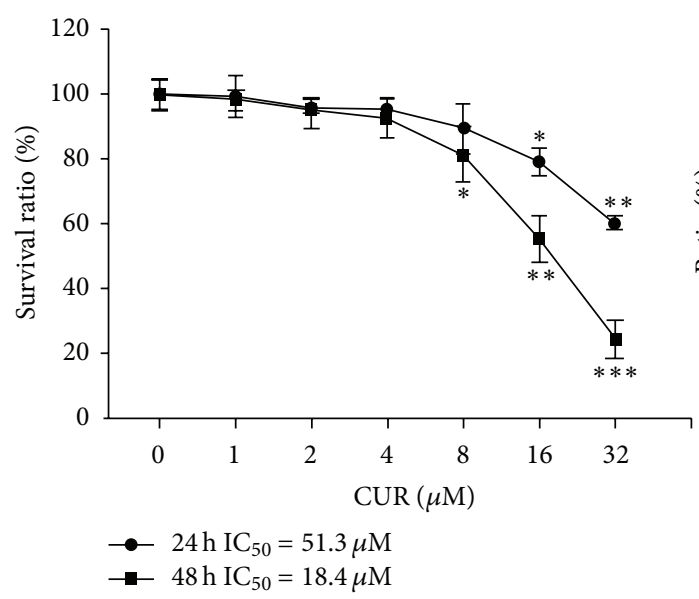

(a)
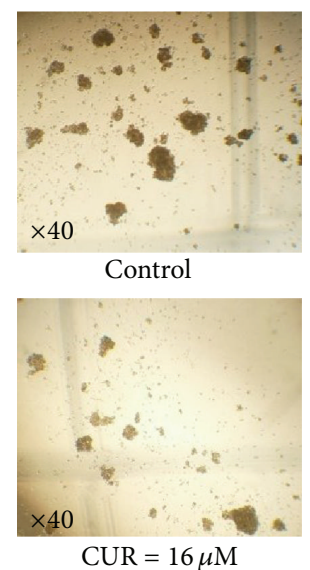
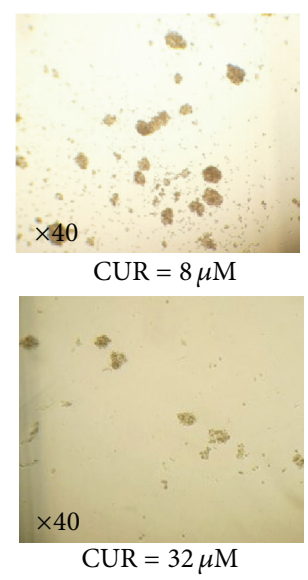

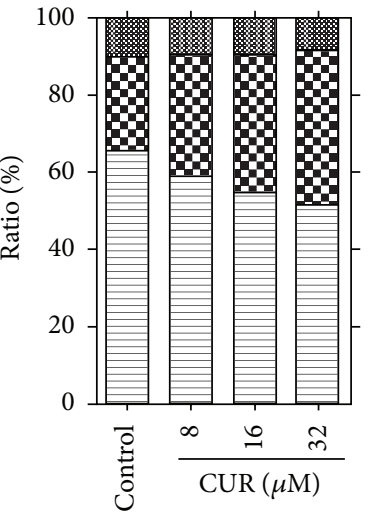

ॠ $2 / \mathrm{M} \boxminus \mathrm{G} 0 / \mathrm{G} 1$ EI $\mathrm{S}$

(b)

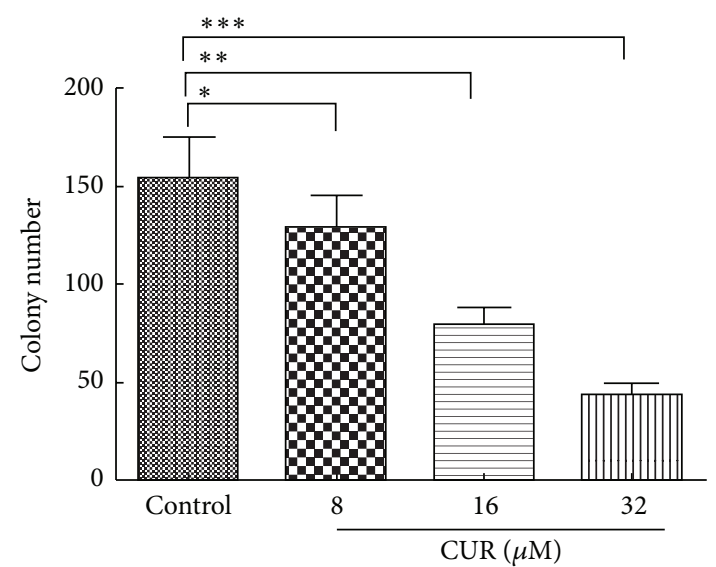

(c)

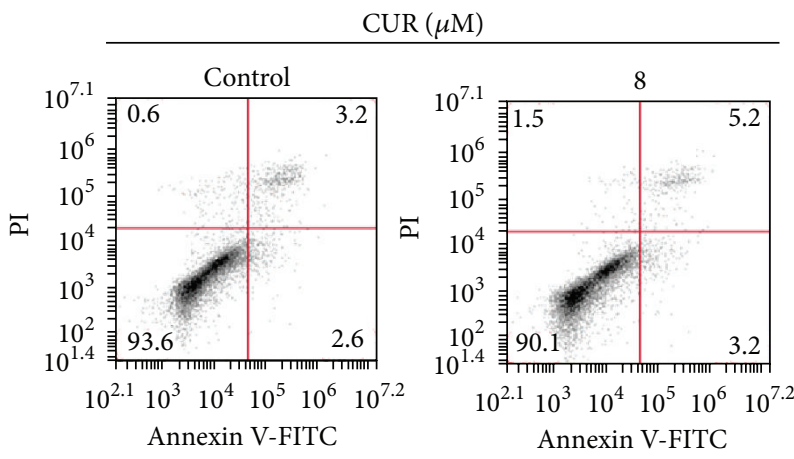

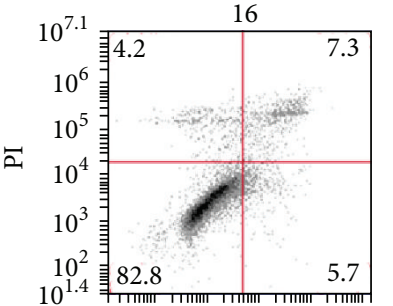

$\begin{array}{llllll}10^{2.1} & 10^{3} & 10^{4} & 10^{5} & 10^{6} & 10^{7.2}\end{array}$ Annexin V-FITC

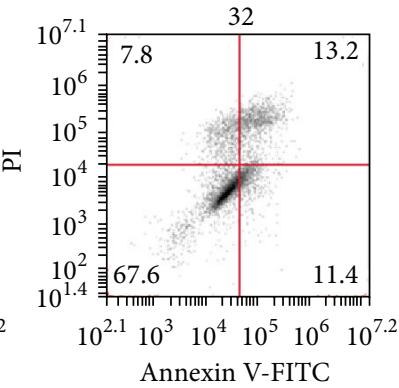

Figure 2: Continued. 


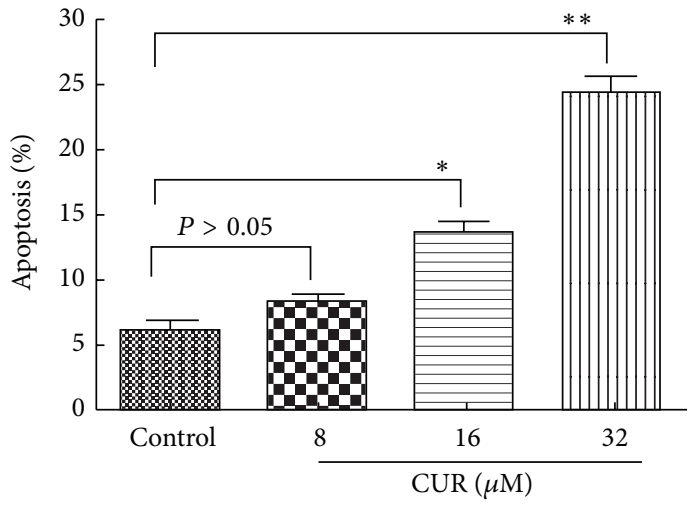

(d)

FIGURE 2: CUR suppressed cell growth, induced S phase arrest, and induced cell apoptosis in KGla cells. (a) KGla cells were treated with different concentrations of CUR for 24 or $48 \mathrm{~h}$. MTT assays were performed. (b) KGla cells were treated with different concentrations of CUR for $48 \mathrm{~h}$ and analyzed for DNA content by flow cytometry. (c) KGla cells were treated with CUR and inoculated in methylcellulose for 14 days and then observed under a right microscope (magnification $\times 40$ ). The graph displays means \pm SD of three independent experiments. ${ }^{*} P<0.05,{ }^{* *} P<0.01$, and ${ }^{* * *} P<0.001$ (compared with control). (d) KGla cells were treated with different concentrations of CUR for $48 \mathrm{~h}$ and analyzed by flow cytometry. The graph displays means \pm SD of three independent experiments. ${ }^{*} P<0.05,{ }^{* *} P<0.01$ (compared with control).

13.0 and Graphpad Prism 5 software. Means of different groups were compared using one-way ANOVA followed by Bonferroni multiple comparison to evaluate the differences between two groups under multiple conditions. If the date failed the normality test, the Kruskal-Wallis one-way ANOVA on ranks was used for data that failed the normality test. A value of $P<0.05$ was considered statistically significant. Compusyn software was used to evaluate the synergistic effects of drug combinations. The combination index (CI) was generated by Compusyn software, where $\mathrm{CI}<1, \mathrm{CI}=1$, and CI $>1$ indicated synergism, additive effect, and antagonism, respectively.

\section{Results}

3.1. $\mathrm{CD} 34^{+} \mathrm{CD} 38^{-} \mathrm{KG1a}$ Cells Were Insensitive to BUS. The percentages of $\mathrm{CD} 34^{+} \mathrm{CD} 38^{-}$cells were $92.3 \%$ in KGla cells, but no $\mathrm{CD} 34^{+} \mathrm{CD} 38^{-}$cells were detected among the HL-60 cells (Figure 1(a)). KGla and HL-60 cell lines were treated with various concentrations of BUS for $48 \mathrm{~h}$ followed by cell viability and apoptosis analyses. BUS suppressed proliferation and induced apoptosis in more mature HL-60 cells, but not in KGla cells (Figures $1(\mathrm{~b})$ and $1(\mathrm{c})$ ). The $\mathrm{IC}_{50}$ values for BUS were $22523.1 \mu \mathrm{M}$ in KGla cells and $354.5 \mu \mathrm{M}$ in HL-60 cells, respectively. The apoptotic rate was significantly higher in HL-60 cells, compared with KGla cells. These results indicated that leukemia stem-like KGla cells were insensitive to BUS and exhibited drug resistance.

\subsection{CUR Inhibited Cell Growth and Induced Cell Apoptosis} in KGla Cells. KGla cells were treated with various concentrations of CUR $(0-32 \mu \mathrm{M})$ for 24 and $48 \mathrm{~h}$ and the cytotoxic effects were detected by MTT assay. CUR exhibited dose- and time-dependent cytotoxic effects in KGla cells (Figure 2(a)). The $\mathrm{IC}_{50}$ values at 24 and $48 \mathrm{~h}$ were $51.3 \mu \mathrm{M}$ and
18.4 $\mu \mathrm{M}$, respectively. The antiproliferation effect of CUR in KGla cells was confirmed further by colony formation assays. CUR suppressed colony formations in a dose-dependent manner (Figure 2(c)). To determine if CUR-induced growth inhibition was related to the cell cycle arrest, KGla cells were exposed to CUR for $48 \mathrm{~h}$ followed by detection by flow cytometry. CUR induced $S$ phase arrest in KGla cells (Figure 2(b)). Treatment with $32 \mu \mathrm{M}$ CUR significantly increased the percentage of cells in S phase from $24.14 \%$ to $40.08 \%$. We investigated the effect of CUR for $48 \mathrm{~h}$ on early and late apoptosis in KGla cells by annexin V analysis. CUR induced apoptosis in a dose-dependent manner in KGla cells (Figure 2(d)). These results demonstrated that CUR could inhibit cell growth and induce apoptosis in KGla cells.

3.3. CUR Increased BUS-Induced Apoptosis by Downregulating Procaspase-3 followed by PARP Degradation in KGla Cells. We determined if CUR could increase BUS-induced apoptosis in KGla cells by examining proapoptotic effects of CUR and BUS alone and in combination (CUR + BUS) using annexin V/PI. Apoptosis was significantly increased in CUR + BUS group, compared with CUR- or BUS-alone groups (Figure 3(a)). For instance, apoptotic rates in cells treated with $16 \mu \mathrm{M}$ CUR, $80 \mu \mathrm{M}$ BUS, and the combination groups were $15.6 \pm 1.5 \%, 5.7 \pm 0.7 \%$, and $28.3 \pm 0.8 \%$, respectively. Western blot analysis also demonstrated that the markers of apoptosis procaspase-3 cleaved PARP were significantly regulated in combination groups (Figure $3(\mathrm{~b})$ ). These results indicated that CUR significantly enhanced BUS-induced apoptosis.

3.4. CUR Synergistically Enhanced the Cytotoxic Effect of BUS in KGla Cells. We investigated the ability of CUR to enhance the cytotoxic effect of BUS by treating KGla cells with combinations of the two drugs at different doses but 


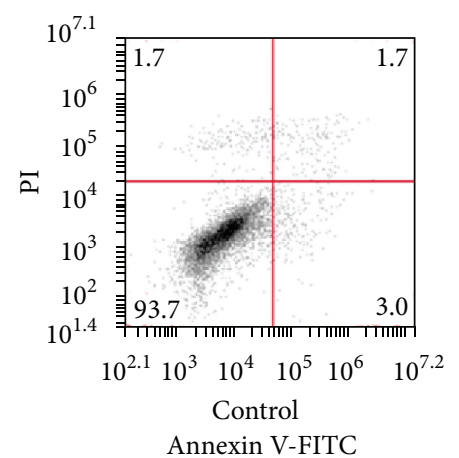

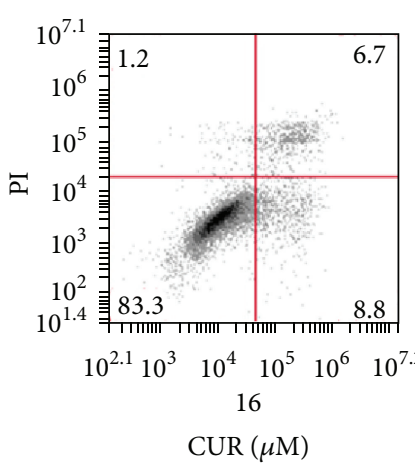

Annexin V-FITC

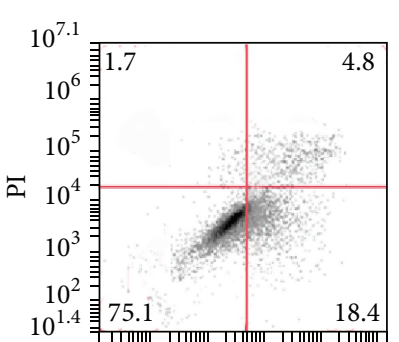

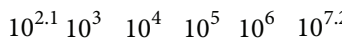

32

CUR $(\mu \mathrm{M})$

Annexin V-FITC

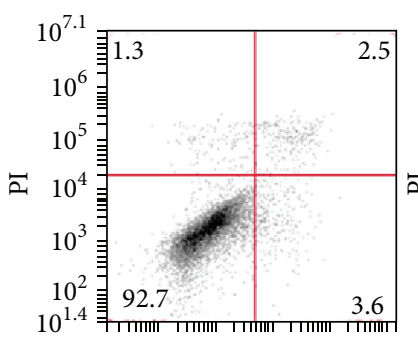

$\begin{array}{llllll}10^{2.1} & 10^{3} & 10^{4} & 10^{5} & 10^{6} & 10^{7.2}\end{array}$

80

$\operatorname{BUS}(\mu \mathrm{M})$

Annexin V-FITC

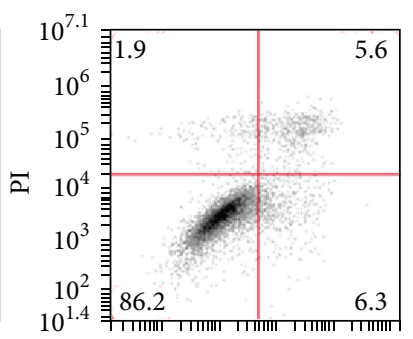

$\begin{array}{llllll}10^{2.1} & 10^{3} & 10^{4} & 10^{5} & 10^{6} & 10^{7.2}\end{array}$

160

BUS $(\mu \mathrm{M})$

Annexin V-FITC
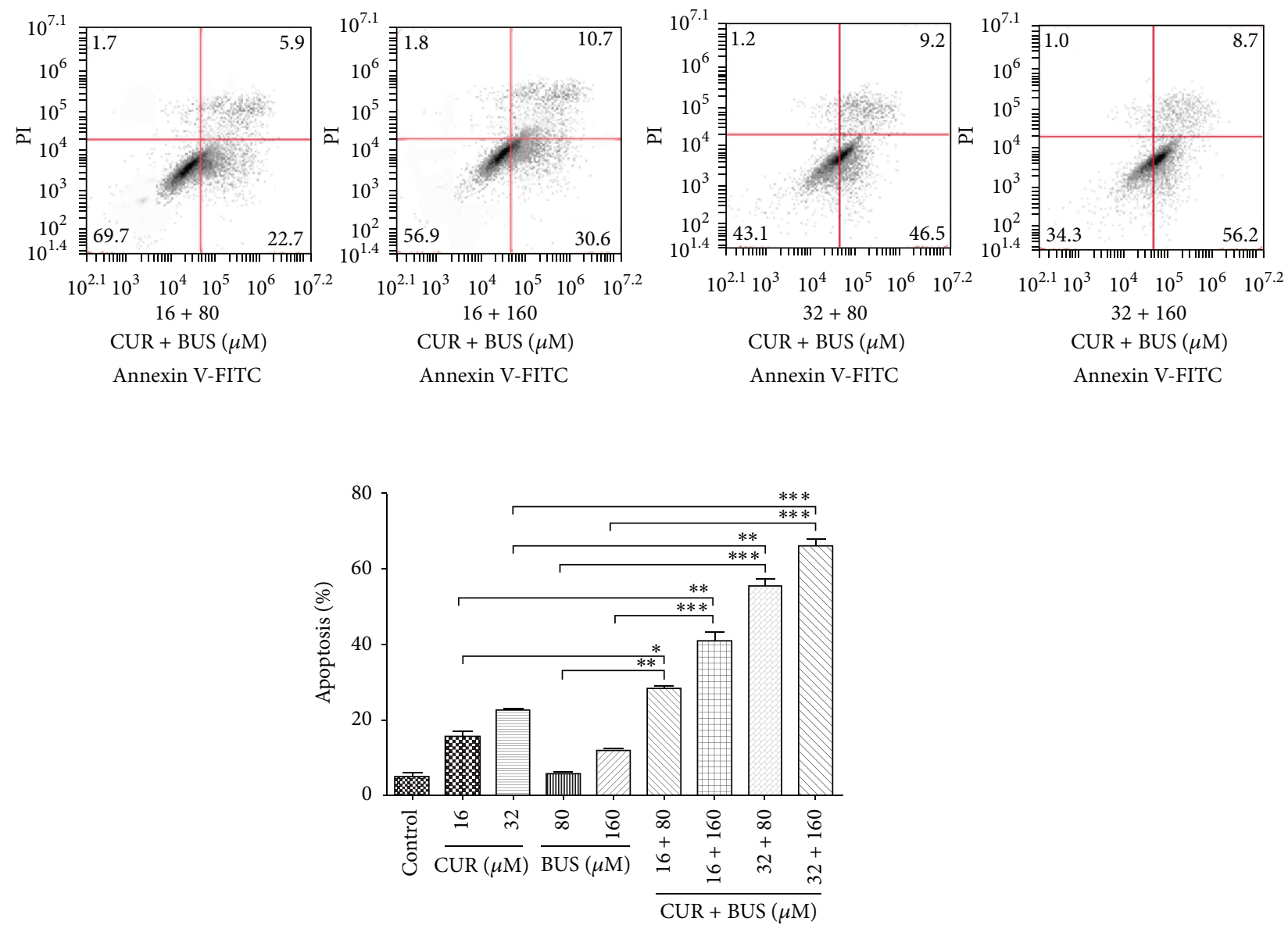

(a)

Figure 3: Continued. 

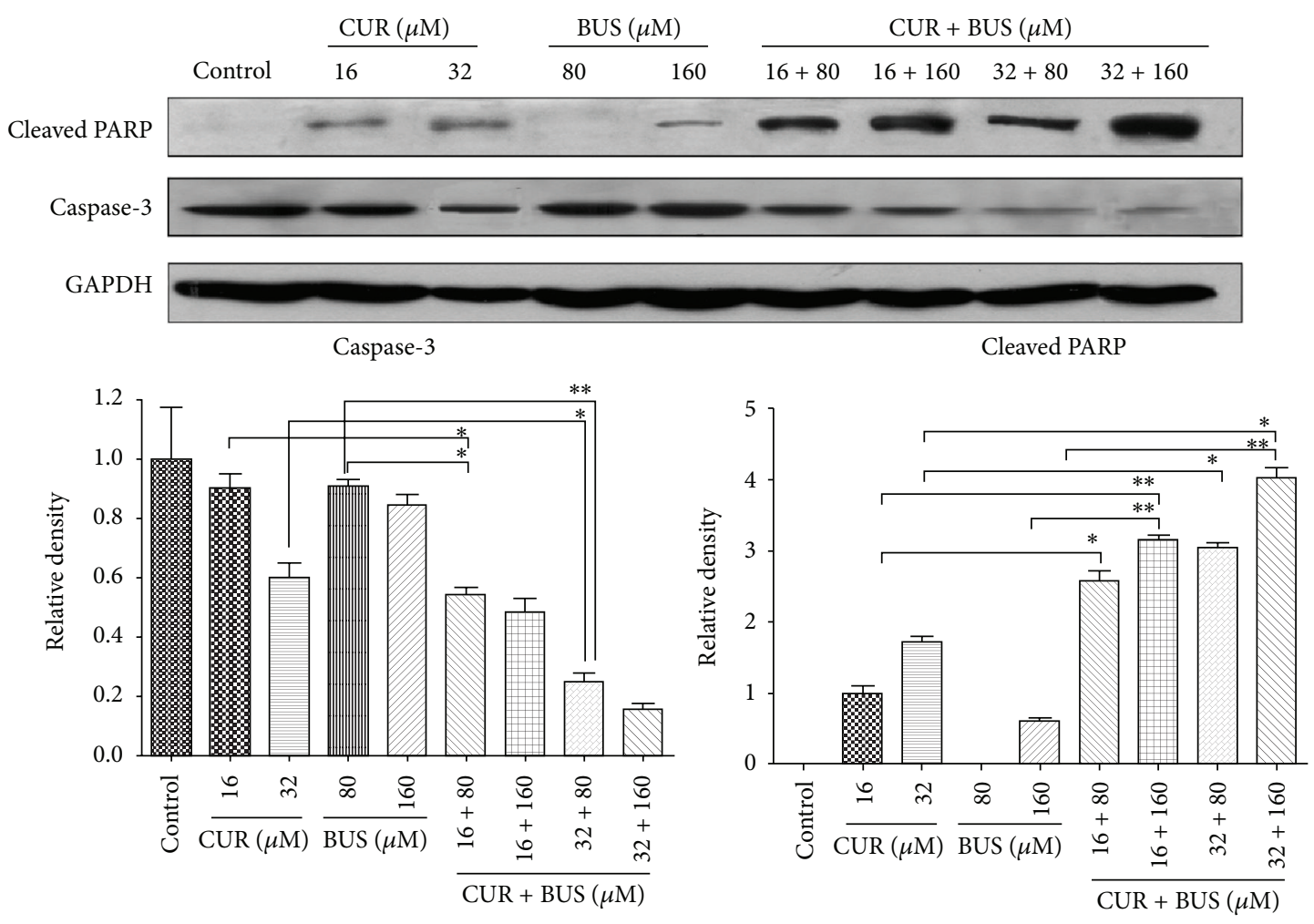

(b)

FIGURE 3: CUR increased BUS-induced apoptosis by downregulating procaspase-3 followed by PARP degradation in KGla cells. (a, b) KGla cells were treated with different concentrations of CUR or BUS alone or CUR + BUS for $48 \mathrm{~h}$ and analyzed by flow cytometry (a) and western blot (b). The graphs represent means $\pm \mathrm{SD}$ of three independent experiments. ${ }^{*} P<0.05,{ }^{* *} P<0.01$, and ${ }^{* * *} P<0.001$.

in a constant ratio (CUR to BUS: $8 \mu \mathrm{M}$ to $80 \mu \mathrm{M}, 16 \mu \mathrm{M}$ to $160 \mu \mathrm{M}$, and $32 \mu \mathrm{M}$ to $320 \mu \mathrm{M}$, resp.) for $48 \mathrm{~h}$. Synergistic effects were estimated using Compusyn software. Cotreatment with all doses exhibited synergistic effects in KGla cells (Figures 4(a) and 4(b)). For example, $16 \mu \mathrm{M}$ CUR plus $80 \mu \mathrm{M}$ BUS resulted in a proliferation inhibition of $60.20 \%$ (Figure $4(\mathrm{c})$ ), compared with CUR $(44.40 \%)$ and BUS alone (4.53\%), indicating a synergistic effect $(\mathrm{CI}=0.733)$, in accord with the result of apoptosis assays. Cotreatment with $16 \mu \mathrm{M}$ CUR and $80 \mu \mathrm{M}$ BUS for $48 \mathrm{~h}$ also induced S and G2/M phase arrest in KGla cells (Figure 4(d)), which may represent one of the mechanisms responsible for the synergism.

3.5. Effects of BUS and CUR on Protein Expression in KG1a Cells. We investigated the molecular mechanisms responsible for CUR-induced apoptosis and enhanced BUS-induced apoptosis in KGla cells treated with $16 \mu \mathrm{M}$ CUR, $80 \mu \mathrm{M}$ BUS, and their combination by detecting expression levels of 43 apoptosis-related proteins using RayBio human apoptosis arrays. The threshold values of fold-change were usually set at $\leq 0.667$ or $\geq 1.5$. Three proteins (Bcl-2-associated death promoter (BAD), caspase-3, and HTRA) were upregulated and four proteins (Bcl-2, cellular inhibitor of apoptosis2 (cIAP-2), survivin, and X-linked inhibitor of apoptosis (XIAP)) were downregulated in CUR group and combination group (Table 1; Figure 5(a)). Survivin was significantly more downregulated in the combination group compared with the CUR group. This result was further confirmed by western blot analysis (Figure 5(b)). Survivin is known to be an important antiapoptosis protein that participates in the modulation of apoptosis by various signal pathways. We therefore considered that survivin was a likely key factor in CUR-induced apoptosis and BUS sensitivity in KGla cells.

3.6. Suppression of Survivin with YM155 Could Induce Apoptosis and Increase the Susceptibility to BUS in KGla Cells. We clarified the role of CUR-induced survivin downregulation in sensitization of KGla cells to BUS by suppressing survivin expression using the specific inhibitor YM155. The proapoptotic effect and sensitivity to BUS were evaluated by flow cytometry. The cytotoxic activity of YM155 in KGla cells was detected by MTT assays. YM155 exhibited time- and dose-dependent growth-inhibitory effects in KGla cells (Figure 6(a)). The $\mathrm{IC}_{50}$ values of 24 and $48 \mathrm{~h}$ were $8.86 \mathrm{ng} / \mathrm{mL}$ and $2.43 \mathrm{ng} / \mathrm{mL}$, respectively. The $\mathrm{YM} 155 \mathrm{IC}_{50}$ of $2.43 \mathrm{ng} / \mathrm{mL}$ was used in subsequent experiments. KGla cells were exposed to $2.43 \mathrm{ng} / \mathrm{mL}$ YM155 and $80 \mu \mathrm{M}$ BUS alone or in combination for $48 \mathrm{~h}$ and early and late apoptotic rates were then examined. YM155-induced apoptosis (14.90\%) (Figure 6(b)) was similar to CUR-induced apoptosis in KGla cells $(15.50 \%, 16 \mu \mathrm{M}$, Figure $3(\mathrm{a}))$. Suppression of survivin 


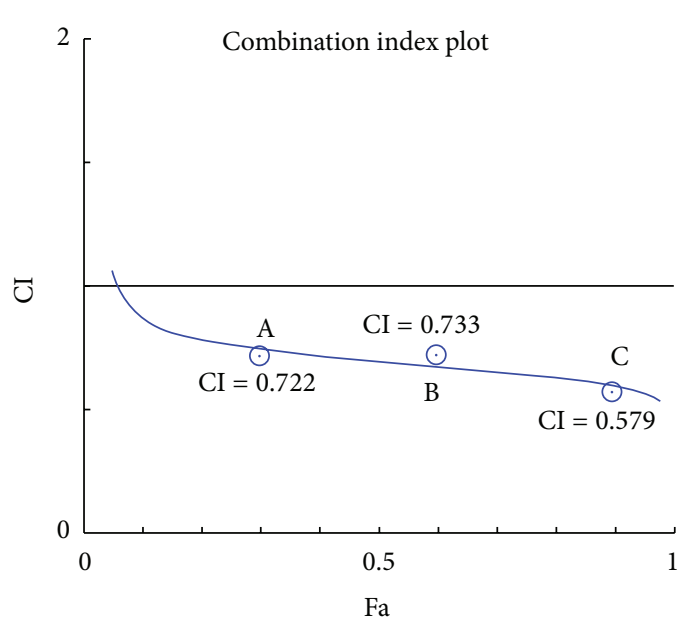

$\odot \mathrm{CUR}+\mathrm{BUS}$ (a)

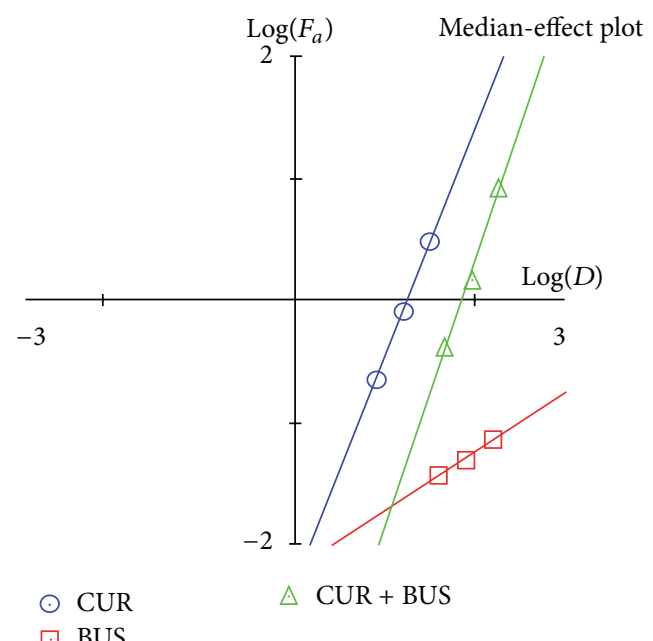

(b)
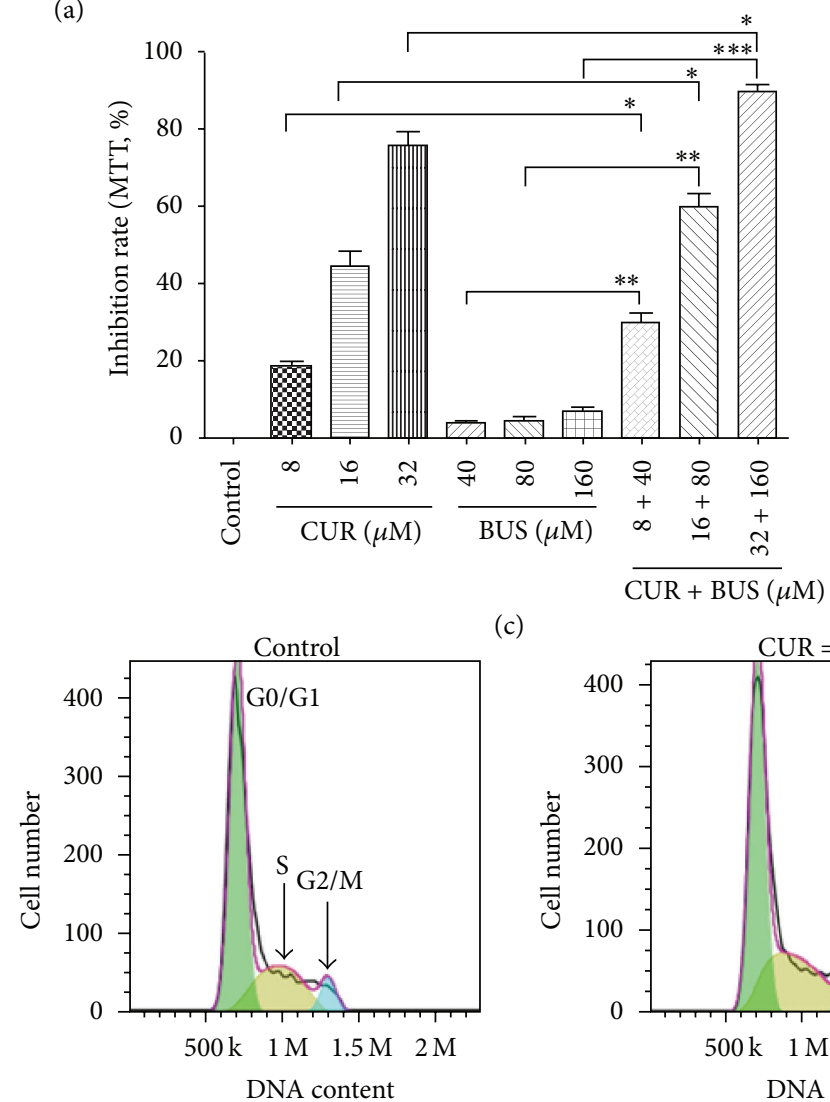

c)
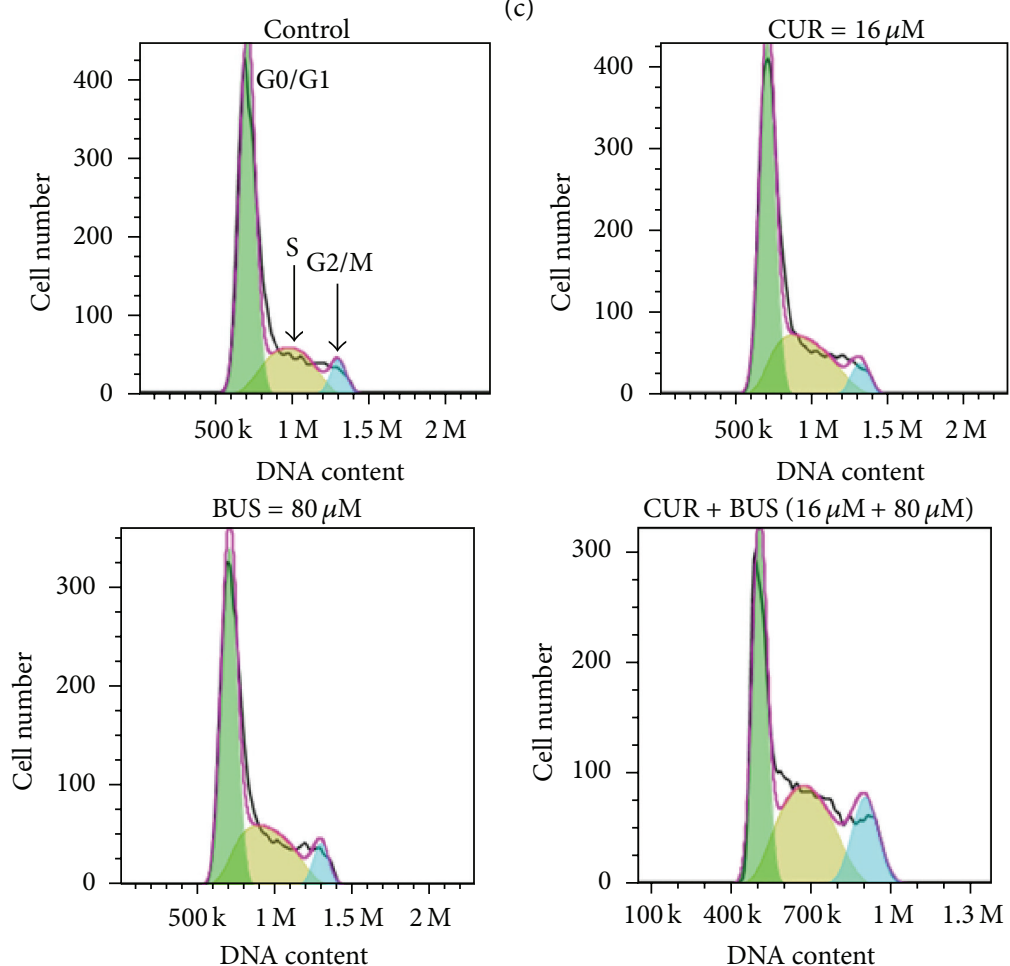

Figure 4: Continued. 


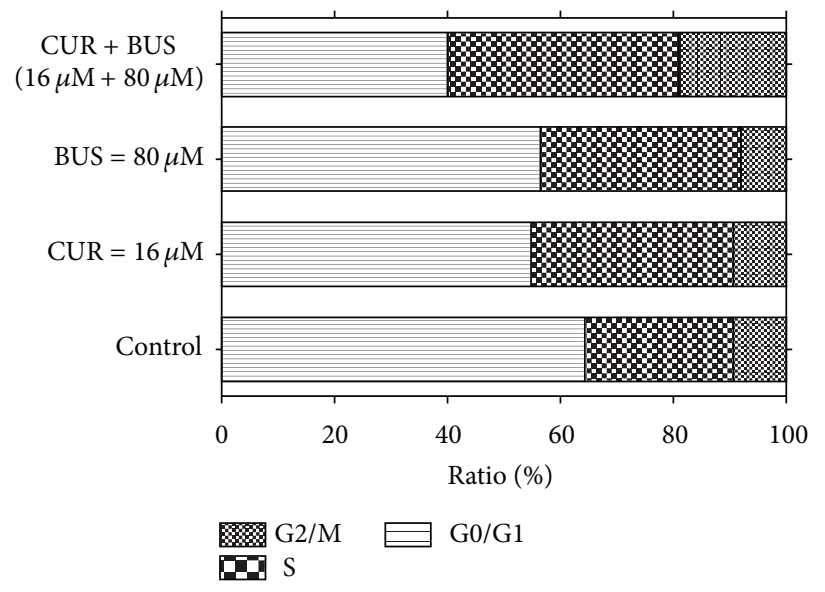

(d)

FIGURE 4: CUR synergistically enhanced the cytotoxic effect of BUS in KGla cells. KGla cells were exposed to CUR + BUS at different doses but in a constant ratio (CUR to BUS: $8 \mu \mathrm{M}$ to $80 \mu \mathrm{M}, 16 \mu \mathrm{M}$ to $160 \mu \mathrm{M}$, and $32 \mu \mathrm{M}$ to $320 \mu \mathrm{M}$, resp.) for $48 \mathrm{~h}$ examined by MTT assay. (a, b) CI-effect plots and median-effect plots were generated using Compusyn software. The points A, B, and C represent CI values for the three combination groups, respectively. (c) The graph displays means $\pm \mathrm{SD}$ of three independent experiments. ${ }^{*} P<0.05$, ${ }^{* *} P<0.01$, and ${ }^{* * *} P<0.001$. (d) KGla cells were treated with CUR or BUS alone or CUR + BUS for $48 \mathrm{~h}$ and analyzed with flow cytometry. The percentages of cells in S and G2/M phases were significantly higher in CUR + BUS group compared with the CUR- or BUS-alone group.

by YM155 increased the susceptibility to BUS, with a BUSinduced apoptotic rate of $40.36 \%$, compared with $8.67 \%$ for BUS alone. These results revealed that suppression of survivin could contribute to CUR-induced apoptosis and the synergistic effect of CUR and BUS in KGla cells.

\section{Discussion}

LSCs were a rare population of cells in patients with leukemia. They possess characteristics of self-renewal, chemotherapy resistance, and immune resistance [20-22]. LSCs were thus commonly regarded as the origin of leukemia relapse and refractory $[12,23]$. LSCs have been reported to demonstrate a CD $34^{+} \mathrm{CD} 38^{-}$phenotype $[10,12,24,25]$, reflected by the acute immature myeloid leukemia cells KGla cell line, which expresses high level of CD34 and lacks CD38. We also provided the first demonstration that leukemia stemlike KG1 cells were insensitive to BUS according to MTT assays and annexin V/PI assays, compared with the more mature acute promyelocyte leukemia HL-60 cells. KGla cells have previously been shown to be resistant to the common chemotherapeutic agent daunorubicin [12]. CD $34^{+} \mathrm{CD} 38^{-}$ KGla cells maybe thus provide an ideal model of LSCs, in accord with previous studies $[12,26]$.

CUR and its analogs have been showed to suppress the growth of various leukemia cells, including U937 cells [27, 28], K562 chronic myeloid leukemia cells [27], and HL-60 acute promyelocyte leukemia cells $[29,30]$, but its effects on LSCs have not been determined. CUR inhibited proliferation and induced $S$ phase arrest and apoptosis in leukemia stemlike KGla cells. CUR was previously shown to target cancer cells or cancer stem cells by several mechanisms, including autophagy, G2/M phase arrest, and apoptosis in hepatoma cells (HepG2, SMMC-7721, and BEL-7402) [31], reducing the expression of stem cell markers (DCLK1/Lgr5/CD44) in colon cancer stem-like HCT-116 [32], and reducing microtentacles and preventing reattachment in breast cancer stemlike cells [33]. CUR has thus demonstrated indeed extensive anticancer effects in various tumors and has been shown to modulate numerous targets including the activation of transcription factors (NF-kB, STAT3, and AP-1), receptors (CXCR-4, HER-2, and IL-8), kinases (EGFR, ERK, and JAK), cytokines (TNF, IL), and others (cyclin-D1/E,XIAP-1) [15, 34]. Unfortunately, the mechanism of $S$ phase arrest induced by CUR was not explored further in depth in this study. In a word, CUR exhibited an inhibitory effect on leukemia stemlike KGla cells, which was particularly worthy of attention.

Insensitivity of LSCs to conditioning chemotherapeutic drugs such as BUS is a major reason for leukemia relapse after HSCT. In this study, KGla cells displayed resistance to BUS, indicated by a lack of apoptosis induction. We there explored the effects of the combination of CUR and BUS on apoptosis in KGla cells. Encouragingly, CUR markedly enhanced BUS-induced apoptosis, as confirmed by annexin V/PI and western blot analysis. Similarly, the combination of various concentrations of CUR and BUS produced a synergistic antiproliferation effect in KGla cells. Accumulating evidence suggests that CUR potentiates the effect, including enhancing the antiapoptotic effects of chemotherapeutic drugs such as 5-fluorouracil, bortezomib, FOLFOX, and paclitaxel in vitro or in vivo [35-39]. The results of the current study suggested that CUR has the potential to be a powerful chemosensitizing agent in various cancer cells, including cancer stem cells (CSCs). Notably, Yu et al. demonstrated that CUR either alone or together with FOLFOX could efficiently eliminate FOLFOX-resistant colon cancer stem cells [36]. However, the effects of the combination of CUR with BUS on cancer stem cells, especially LSCs, have not been reported. BUS is 


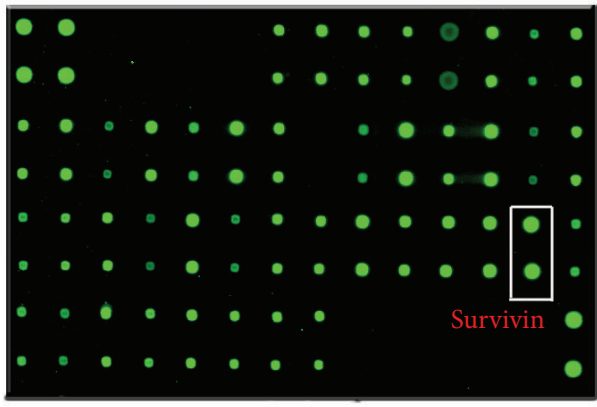

Control

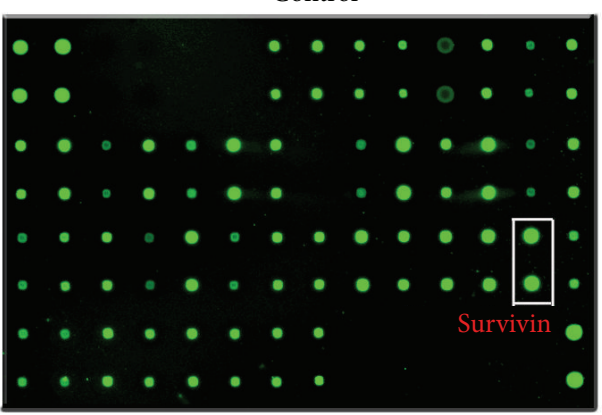

BUS

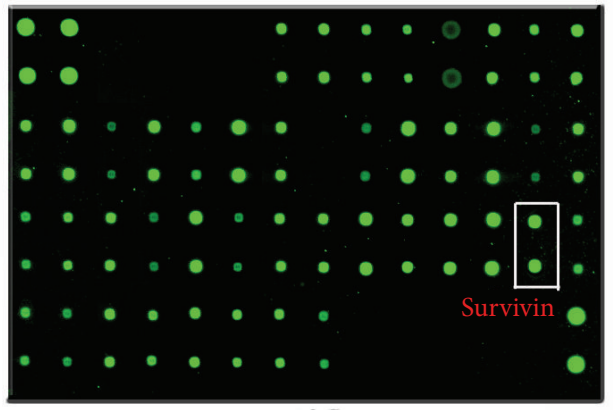

CUR

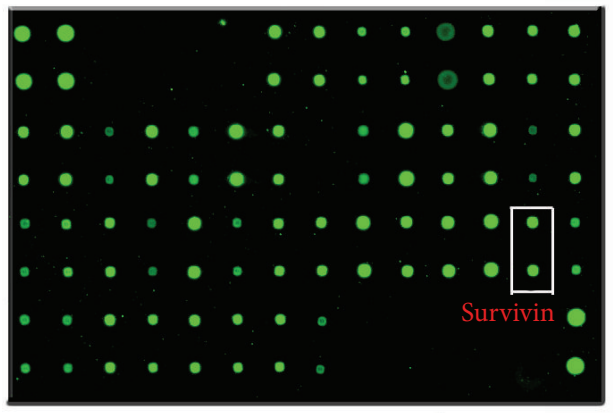

CUR + BUS

(a)

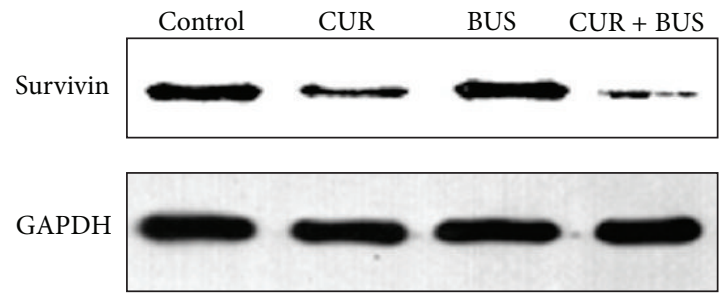

(b)

FIGURE 5: Expression of antiapoptosis protein survivin in KGla cells. (a, b) KGla cells were treated with CUR (16 $\mu \mathrm{M})$, BUS (80 $\mu \mathrm{M})$, or CUR + BUS for $48 \mathrm{~h}$ tested by protein arrays kit (a) as described in "methods." The intensities of green fluorescence spots represent survivin expression. Survivin expression was significantly decreased in CUR and CUR + BUS groups, compared with controls, the same as the results analyzed by western blot analysis.

well-known conditioning agent for HSCT, and its ability to eliminate LSCs is vital for the successful cure of leukemia in patients undergoing this treatment. Gerber et al. pointed out that minimal residual disease detected during complete remission was enriched for $\mathrm{CD} 34^{+} \mathrm{CD} 38^{-} \mathrm{ALDH}^{\text {int }}$ leukemia cells, which were highly correlated with subsequent clinical relapse [25]. Combined treatment with CUR may allow a reduction in the clinical dose of BUS for HSCT, with the potential for reducing NRM. Nakane et al. showed that reduced-intensity conditioning by BUS was associated with lower NRM in patients undergoing unrelated bone marrow transplantation [40]. The results of the current study showed a significant reduction in the percentage of cells in G0/G1 phase in the combination group (Figure $4(\mathrm{~d})$ ), suggesting that cells in G0/G1 phase were more sensitive to this drug combination. Interestingly, cancer stem cells (including LSCs) tend to remain in quiescent phase and possess drug resistance [41-44]. The discovery that CUR could sensitize leukemia stem-like KGla cells to BUS suggested that further studies are warranted, especially with a view to elucidating the mechanism responsible for this effect.

The results of apoptosis arrays showed that seven apoptosis-related proteins were significantly modulated in KGla cells treated with CUR and CUR + BUS (Figure 5(a); Table 1). A mechanistic diagram was thus presented in Figure 7. Activated caspase-3 is the common effector caspase of the intrinsic and extrinsic pathways of apoptosis and is thus a marker of apoptosis [45]. Activated caspase- 9 is an upstream protein effector that may stimulate caspase-3 [45]. XIAP inhibits caspases, including caspase-3 and caspase-9, by direct physical interactions [46]. Interestingly, we found that XIAP expression in KGla cells was downregulated by CUR and especially by CUR + BUS. cIAP-2, another member of inhibitor of apoptosis (IAP) family, was downregulated in the same two groups. cIAP-2 could bind caspase- 3 and mark it for proteasomal degradation rather than inhibit it 
TABLE 1: Expression of apoptosis-related proteins in various treated groups.

\begin{tabular}{|c|c|c|c|c|c|c|c|}
\hline Name & Control & CUR & BUS & CUR + BUS & $\begin{array}{l}\text { CUR/control } \\
\text { (fold-change) }\end{array}$ & $\begin{array}{l}\text { BUS/control } \\
\text { (fold-change) }\end{array}$ & $\begin{array}{c}\text { CUR + BUS/control } \\
\text { (fold-change) }\end{array}$ \\
\hline BAD & 9754.372 & 11939.256 & 8854.383 & 21865.952 & 1.224 & 0.908 & 2.242 \\
\hline BAX & 11665.057 & 11534.453 & 11072.484 & 10875.680 & 0.989 & 0.949 & 0.932 \\
\hline Bcl-2 & 5201.059 & 4032.165 & 4793.070 & 2454.999 & 0.775 & 0.922 & 0.472 \\
\hline Bcl-w & 3934.754 & 3354.182 & 3464.131 & 3789.188 & 0.852 & 0.880 & 0.963 \\
\hline BID & 1241.608 & 1159.421 & 1473.127 & 1702.301 & 0.934 & 1.186 & 1.371 \\
\hline BIM & 8791.171 & 7763.556 & 8225.960 & 8295.705 & 0.883 & 0.936 & 0.944 \\
\hline Caspase-3 & 5414.356 & 9883.863 & 4966.096 & 12514.137 & 1.825 & 0.917 & 2.311 \\
\hline Caspase-8 & 6636.880 & 7681.166 & 7505.017 & 7338.462 & 1.157 & 1.131 & 1.106 \\
\hline CD40 & 7229.618 & 5707.767 & 6661.514 & 5874.868 & 0.789 & 0.921 & 0.813 \\
\hline CD40L & 16087.024 & 12956.135 & 15884.779 & 14392.403 & 0.805 & 0.987 & 0.895 \\
\hline cIAP-2 & 1971.306 & 1308.320 & 1917.709 & 702.301 & 0.664 & 0.973 & 0.356 \\
\hline CytoC & 8302.835 & 6758.989 & 8156.269 & 7832.756 & 0.814 & 0.982 & 0.943 \\
\hline DR6 & 3370.080 & 2669.250 & 3008.736 & 2958.532 & 0.792 & 0.893 & 0.878 \\
\hline Fas & 25854.867 & 22694.082 & 24157.601 & 23693.574 & 0.878 & 0.934 & 0.916 \\
\hline FasL & 7155.526 & 6020.454 & 7420.907 & 7047.913 & 0.841 & 1.037 & 0.985 \\
\hline HSP27 & 2395.653 & 2109.392 & 2279.382 & 2807.833 & 0.881 & 0.951 & 1.172 \\
\hline HSP60 & 24408.943 & 20936.090 & 30040.496 & 23881.647 & 0.858 & 1.231 & 0.978 \\
\hline HSP70 & 6055.367 & 7532.267 & 6146.040 & 6971.961 & 1.244 & 1.015 & 1.151 \\
\hline HTRA & 10052.830 & 20991.713 & 12382.184 & 26027.247 & 2.088 & 1.232 & 2.589 \\
\hline IGF-I & 1772.604 & 1407.585 & 1857.630 & 1717.974 & 0.794 & 1.048 & 0.969 \\
\hline IGF-II & 7991.872 & 8066.316 & 10003.085 & 9495.273 & 1.009 & 1.252 & 1.188 \\
\hline IGFBP-1 & 3060.239 & 2144.135 & 2680.707 & 2416.014 & 0.701 & 0.876 & 0.789 \\
\hline IGFBP-2 & 3750.645 & 2977.966 & 3901.504 & 3569.769 & 0.794 & 1.040 & 0.952 \\
\hline IGFBP-3 & 5321.179 & 3985.511 & 5547.657 & 5313.061 & 0.749 & 1.043 & 0.998 \\
\hline IGFBP-4 & 2012.843 & 1573.358 & 1736.271 & 1873.496 & 0.782 & 0.863 & 0.931 \\
\hline IGFBP-5 & 11366.442 & 9202.906 & 10929.497 & 10428.404 & 0.810 & 0.962 & 0.917 \\
\hline IGFBP-6 & 2354.116 & 1950.567 & 2340.662 & 2413.603 & 0.829 & 0.994 & 1.025 \\
\hline IGF-1sR & 5755.629 & 4286.285 & 5791.576 & 5056.269 & 0.745 & 1.006 & 0.878 \\
\hline Livin & 7478.838 & 6829.468 & 7818.628 & 7778.504 & 0.913 & 1.045 & 1.040 \\
\hline $\mathrm{p} 21$ & 17207.390 & 15850.718 & 18463.352 & 17993.517 & 0.921 & 1.073 & 1.046 \\
\hline p27 & 8486.943 & 7790.358 & 8890.430 & 8879.213 & 0.918 & 1.048 & 1.046 \\
\hline p53 & 9829.587 & 9303.164 & 11354.853 & 11263.882 & 0.946 & 1.155 & 1.146 \\
\hline SMAC & 9838.568 & 10157.840 & 11915.987 & 12549.047 & 1.032 & 1.211 & 1.275 \\
\hline Survivin & 76507.100 & 31134.629 & 81877.505 & 11691.497 & 0.407 & 1.070 & 0.153 \\
\hline sTNF-R1 & 3284.761 & 2747.670 & 3781.346 & 3136.960 & 0.836 & 1.151 & 0.955 \\
\hline sTNF-R2 & 3504.793 & 2428.035 & 3118.079 & 2815.066 & 0.693 & 0.890 & 0.803 \\
\hline TNF-alpha & 2641.505 & 1771.889 & 2802.065 & 2499.200 & 0.671 & 1.061 & 0.946 \\
\hline TNF-beta & 6946.720 & 4871.952 & 6715.585 & 6430.648 & 0.701 & 0.967 & 0.926 \\
\hline TRAILR-1 & 3835.964 & 3031.569 & 4114.182 & 4102.643 & 0.790 & 1.073 & 1.070 \\
\hline TRAILR-2 & 7488.942 & 6315.272 & 7505.017 & 7691.701 & 0.843 & 1.002 & 1.027 \\
\hline TRAILR-3 & 4649.857 & 3717.494 & 4614.036 & 4605.376 & 0.799 & 0.992 & 0.990 \\
\hline TRAILR-4 & 4613.933 & 3900.142 & 4694.541 & 4706.646 & 0.845 & 1.017 & 1.020 \\
\hline XIAP & 5465.996 & 2412.352 & 6570.195 & 1011.597 & 0.441 & 1.202 & 0.185 \\
\hline
\end{tabular}

KGla cells were treated with CUR $(16 \mu \mathrm{M})$, BUS $(80 \mu \mathrm{M})$ alone, or CUR + BUS for $48 \mathrm{~h}$ tested by protein arrays kit. The data represent fluorescence intensities of 43 apoptosis-related proteins. The bold bands indicate proteins that were modulated by CUR or CUR + BUS. The threshold values of fold-change were usually set at $\leq 0.667$ or $\geq 1.5$. 


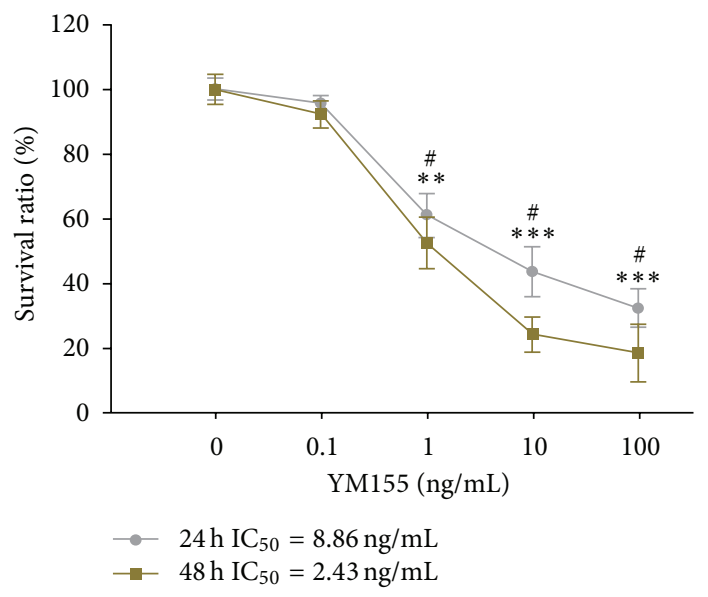

(a)
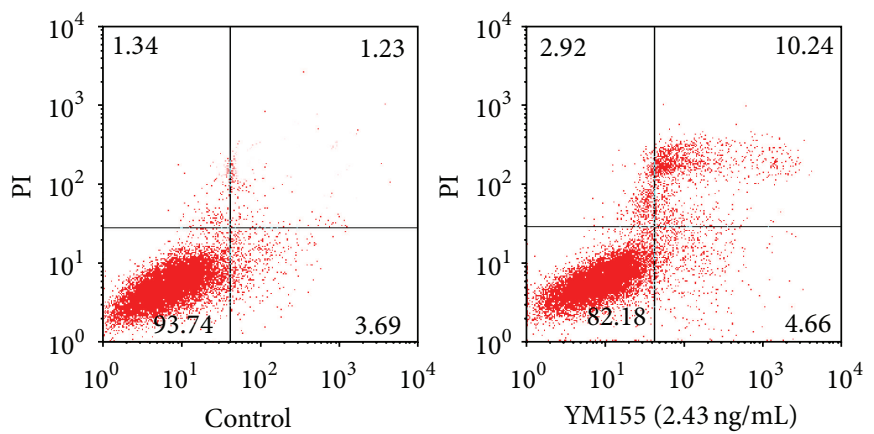

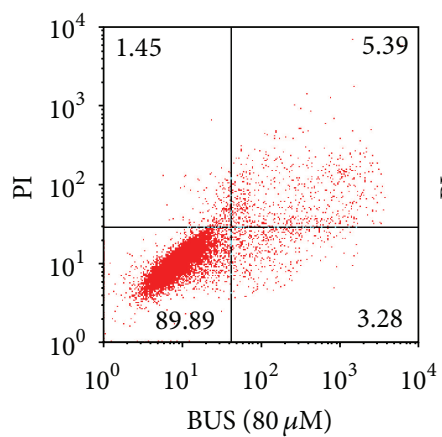

Annexin V-FITC

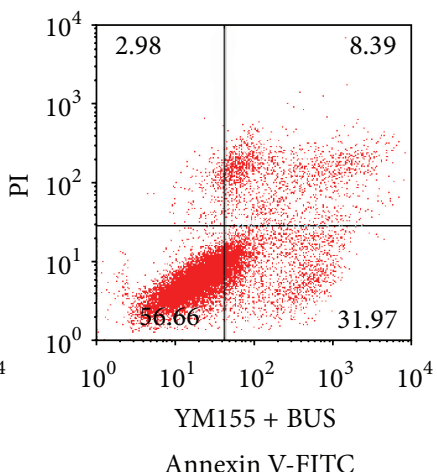

(b)

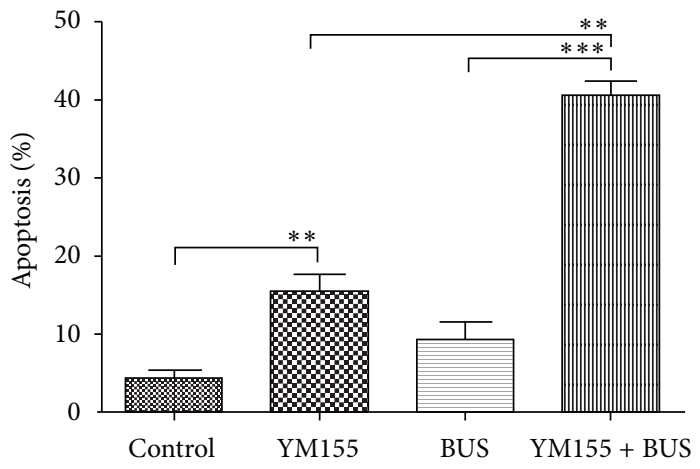

FIGURE 6: Suppression of survivin with YM155 could induce apoptosis and increase the sensitivity to BUS in KGla cells. (a) KGla cells were treated with different concentrations of YM155 for 24 and $48 \mathrm{~h}$ and examined by MTT assay. ${ }^{* *} P<0.01$ and ${ }^{* * *} P<0.001$ (compared with control) and ${ }^{\#} P<0.05$ (compared with 48 h group). (b) KGla cells exposed to YM155 $(2.43 \mathrm{ng} / \mathrm{mL})$ and BUS (80 $\mu$ M) alone or CUR + BUS were analyzed by flow cytometry. The graph displays means $\pm \mathrm{SD}$ of three independent experiments. ${ }^{* *} P<0.01,{ }^{* * *} P<0.001$.

by physical interaction [47]. These results suggest that the downregulation of XIAP and cIAP-2 was closely related to the CUR-induced enhancement of apoptosis in KGla cells. Notably, we provide the first evidence to demonstrate that CUR alone, and especially in combination with BUS, increased the expression of proapoptotic serine protease HTRA-2 in leukemia cells, particularly in leukemia stem-like cells (Table 1). HTRA2 plays a pivotal role in the induction of apoptosis in the response to various stressors, mediating interactions with a variety of inhibiter of IAPs, such as
XIAP and cIAP-1/2, through their BIR domains [48-50]. The neutralization of IAPs causes the activation of caspases $3 / 7 / 9$ and thus contributes to the induction of apoptosis $[48,49]$. Hence, the increase in HTRA-2 observed in the current study may thus be an important mechanism in the downregulation of XIAP and cIAP-2, finally, leading to apoptosis induction and enhancement of apoptosis in CUR + BUS-treated KGla cells.

This study also demonstrated that survivin expression was downregulated by CUR and CUR + BUS (Figures 


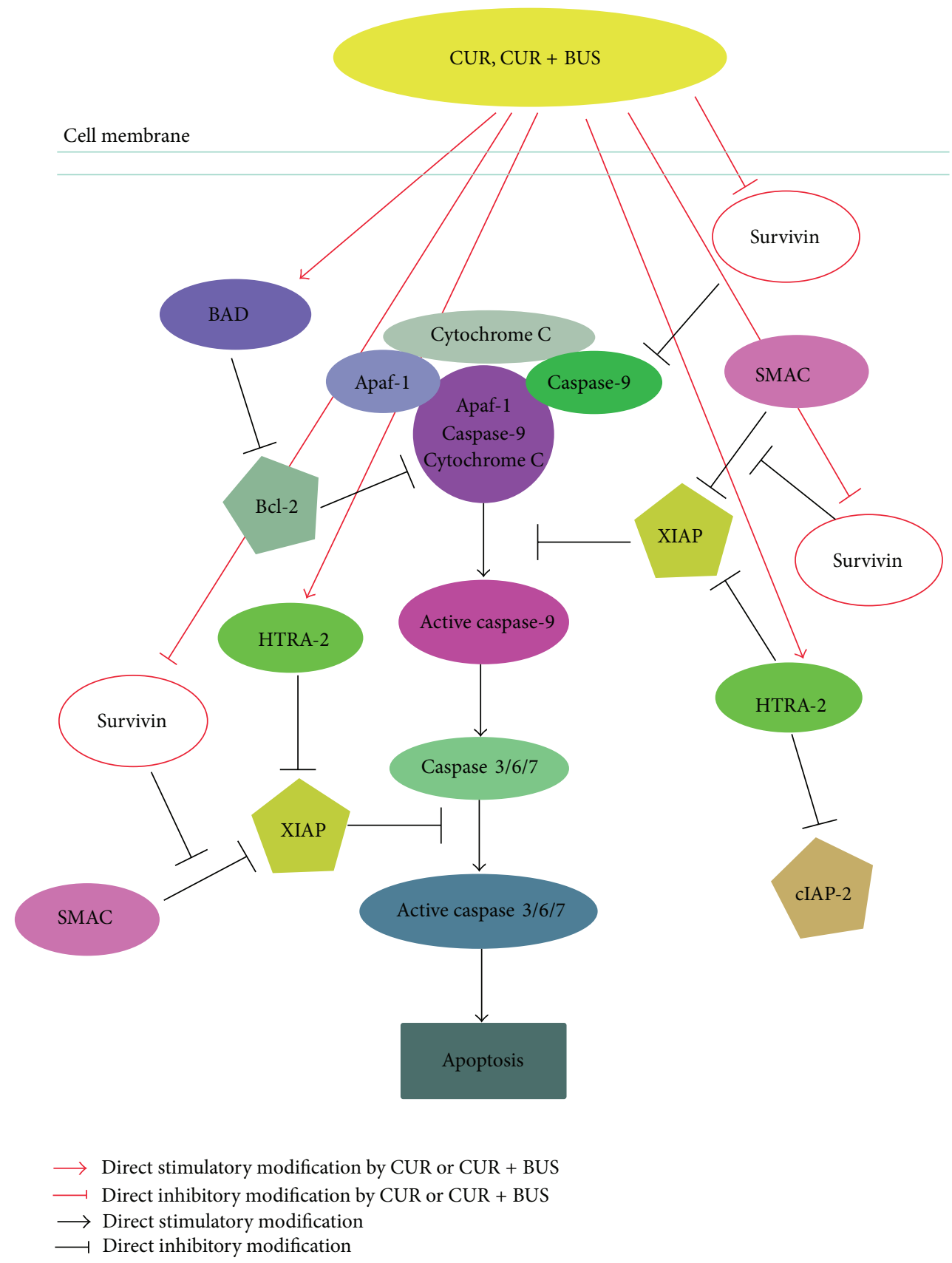

FIGURE 7: Mechanisms of CUR-induced apoptosis and enhanced sensitivity to BUS in KGla cells, indicating the potential role of survivin.

5(a) and 5(b); Table 1). Survivin is an important IAP that tends to be overexpressed in cancer cells [51], including cancer stem cells [52, 53], which exerts antiapoptotic effects via various mechanisms. For example, survivin inhibits caspase-dependent apoptosis through cooperation with XIAP, inhibits the SMAC-XIAP complex, and interferes with caspase-3/caspase-9 [51] (Figure 7). Our results showed that KGla cells overexpressed survivin protein (Figure 5(a)), in accord with the characteristics of leukemia stem-like cells. CUR alone and especially CUR + BUS decreased survivin expression in KGla cells (consistent with the results of apoptosis showed in Figures 3(a) and 3(b)). Growing evidence has demonstrated that downregulating or inhibiting survivin could induce apoptosis and eradicate cancer stem cells or LSCs [52, 54-56]. This suggests that CUR may induce apoptosis and enhance BUS-induced apoptosis by downregulating the expression of survivin in KGla cells. This was confirmed by treating KGla cells with survivin inhibitor YM155 alone or in combination with BUS. YM155 induced apoptosis and enhanced BUS-induced apoptosis in KGla cells, in a similar manner to CUR (Figure 6(b)). Survivin appears to act as a key protein in the mechanisms whereby CUR sensitizes KGla cells to BUS. BAD and Bcl-2 proteins were also shown to be modulated by CUR and CUR + BUS, 
and further studies are warranted to explore their roles in the CUR-induced effects in KGla cells.

In summary, this study demonstrated underlying new mechanisms whereby CUR may overcome BUS insensitivity by downregulating survivin in leukemia stem-like KGla cells. CUR, alone or in combination with BUS, could be a potential anti-LSCs agent for preventing leukemia relapse and reducing the NRM after HSCT. BUS is currently still widely used in the pretreatment of HSCT, but it shows significant side effects and carcinogenicity in patients undergoing HSCT, resulting in danger of being replaced by other conditioning regimens. CUR may solve these issues by combining BUS in the conditioning regimen.

\section{Conflict of Interests}

The authors have no competing interests to declare.

\section{Authors' Contribution}

Guangyang Weng and Yingjian Zeng contributed equally to this work.

\section{Acknowledgments}

The authors would like to thank Yanjie HE (Laboratory of Hematology, Zhujiang Hospital) for assistance with experimental techniques, Pingfang Xia for revising the paper, and Miaorong She for KGla cells. This work was supported by the National Natural Science Foundation of China (Grant no. 30973454).

\section{References}

[1] B. K. Hamilton and E. A. Copelan, "Concise review: the role of hematopoietic stem cell transplantation in the treatment of acute myeloid leukemia," Stem Cells, vol. 30, no. 8, pp. 1581-1586, 2012.

[2] G. L. Phillips, "Allogeneic hematopoietic stem cell transplantation (HSCT) for high-risk acute myeloid leukemia (AML)/myelodysplastic syndrome (MDS): how can we improve outcomes in the near future?" Leukemia Research, vol. 36, no. 12, pp. 1490-1495, 2012.

[3] A. Sureda, M. I. B. Pereira, and P. Dreger, "The role of hematopoietic stem cell transplantation in the treatment of relapsed/refractory Hodgkin's lymphoma," Current Opinion in Oncology, vol. 24, no. 6, pp. 727-732, 2012.

[4] E. D. Thomas, "A review of the results of human marrow transplantation in Seattle," Nihon Ketsueki Gakkai Zasshi, vol. 40, pp. 863-872, 1977.

[5] S. Z. Pavletic, S. Kumar, M. Mohty et al., "NCI first international workshop on the biology, prevention, and treatment of relapse after allogeneic hematopoietic stem cell transplantation: report from the committee on the epidemiology and natural history of relapse following allogeneic cell transplantation," Biology of Blood and Marrow Transplantation, vol. 16, no. 7, pp. 871-890, 2010.

[6] S. Yoshihara, T. Ando, and H. Ogawa, "Extramedullary relapse of acute myeloid leukemia after allogeneic hematopoietic stem cell transplantation: an easily overlooked but significant pattern of relapse," Biology of Blood and Marrow Transplantation, vol. 18, no. 12, pp. 1800-1807, 2012.

[7] M. L. Linenberger, T. Hong, D. Flowers et al., "Multidrugresistance phenotype and clinical responses to gemtuzumab ozogamicin," Blood, vol. 98, no. 4, pp. 988-994, 2001.

[8] M. Dean, T. Fojo, and S. Bates, "Tumour stem cells and drug resistance," Nature Reviews Cancer, vol. 5, no. 4, pp. 275-284, 2005.

[9] S. Pei and C. T. Jordan, "How close are we to targeting the leukemia stem cell?" Best Practice and Research: Clinical Haematology, vol. 25, no. 4, pp. 415-418, 2012.

[10] T. Lapidot, C. Sirard, J. Vormoor et al., "A cell initiating human acute myeloid leukaemia after transplantation into SCID mice," Nature, vol. 367, no. 6464, pp. 645-648, 1994.

[11] D. Fuchs, V. Daniel, M. Sadeghi, G. Opelz, and C. Naujokat, "Salinomycin overcomes ABC transporter-mediated multidrug and apoptosis resistance in human leukemia stem cell-like KGla cells," Biochemical and Biophysical Research Communications, vol. 394, no. 4, pp. 1098-1104, 2010.

[12] M. She, X. Niu, X. Chen et al., "Resistance of leukemic stemlike cells in AML cell line KGla to natural killer cell-mediated cytotoxicity," Cancer Letters, vol. 318, no. 2, pp. 173-179, 2012.

[13] M. Mohty, F. Malard, D. Blaise et al., "Reduced-toxicity conditioning with fludarabine, once-daily intravenous busulfan, and antithymocyte globulins prior to allogeneic stem cell transplantation: results of a multicenter prospective phase 2 trial," Cancer, vol. 121, no. 4, pp. 562-569, 2015.

[14] S. Almog, D. Kurnik, A. Shimoni et al., "Linearity and stability of intravenous busulfan pharmacokinetics and the role of glutathione in busulfan elimination," Biology of Blood and Marrow Transplantation, vol. 17, no. 1, pp. 117-123, 2011.

[15] Y. Jiao, J. T. Wilkinson, X. Di et al., "Curcumin, a cancer chemopreventive and chemotherapeutic agent, is a biologically active iron chelator," Blood, vol. 113, no. 2, pp. 462-469, 2009.

[16] B. van't Land, N. M. A. Blijlevens, J. Marteijn et al., "Role of curcumin and the inhibition of NF-KB in the onset of chemotherapy-induced mucosal barrier injury," Leukemia, vol. 18, no. 2, pp. 276-284, 2004.

[17] Y. Li and T. Zhang, "Targeting cancer stem cells by curcumin and clinical applications," Cancer Letters, vol. 346, no. 2, pp. 197205, 2014.

[18] A. Goel and B. B. Aggarwal, "Curcumin, the golden spice from Indian saffron, is a chemosensitizer and radiosensitizer for tumors and chemoprotector and radioprotector for normal organs," Nutrition and Cancer, vol. 62, no. 7, pp. 919-930, 2010.

[19] A. H. Rahmani, M. A. Al Zohairy, S. M. Aly, and M. A. Khan, "Curcumin: a potential candidate in prevention of cancer via modulation of molecular pathways," BioMed Research International, vol. 2014, Article ID 761608, 15 pages, 2014.

[20] M. M. Ho, D. E. Hogge, and V. Ling, "MDR1 and BCRP1 expression in leukemic progenitors correlates with chemotherapy response in acute myeloid leukemia," Experimental Hematology, vol. 36, no. 4, pp. 433-442, 2008.

[21] G.-M. Zou, "Cancer stem cells in leukemia, recent advances," Journal of Cellular Physiology, vol. 213, no. 2, pp. 440-444, 2007.

[22] L. Ruggeri, A. Mancusi, M. Capanni et al., "Donor natural killer cell allorecognition of missing self in haploidentical hematopoietic transplantation for acute myeloid leukemia: challenging its predictive value," Blood, vol. 110, no. 1, pp. 433-440, 2007. 
[23] M. C. Stubbs and S. A. Armstrong, "Therapeutic implications of leukemia stem cell development," Clinical Cancer Research, vol. 13, no. 12, pp. 3439-3442, 2007.

[24] D. Bonnet and J. E. Dick, "Human acute myeloid leukemia is organized as a hierarchy that originates from a primitive hematopoietic cell," Nature Medicine, vol. 3, no. 7, pp. 730-737, 1997.

[25] J. M. Gerber, B. D. Smith, B. Ngwang et al., "A clinically relevant population of leukemic $\mathrm{CD} 34^{+} \mathrm{CD} 38^{-}$cells in acute myeloid leukemia," Blood, vol. 119, no. 15, pp. 3571-3577, 2012.

[26] L. Hu, D. Cao, Y. Li, Y. He, and K. Guo, "Resveratrol sensitized leukemia stem cell-like KG-la cells to cytokine-induced killer cells-mediated cytolysis through NKG2D ligands and TRAIL receptors," Cancer Biology and Therapy, vol. 13, no. 7, pp. 516526, 2012.

[27] Y. Sánchez, G. P. Simón, E. Calviño, E. de Blas, and P. Aller, "Curcumin stimulates reactive oxygen species production and potentiates apoptosis induction by the antitumor drugs arsenic trioxide and lonidamine in human myeloid leukemia cell lines," Journal of Pharmacology and Experimental Therapeutics, vol. 335, no. 1, pp. 114-123, 2010.

[28] Y.-K. Kwon, J.-M. Jun, S.-W. Shin, J.-W. Cho, and S.-I. Suh, "Curcumin decreases cell proliferation rates through BTG2mediated cyclin D1 down-regulation in U937 cells," International Journal of Oncology, vol. 26, no. 6, pp. 1597-1603, 2005.

[29] S. Derochette, T. Franck, A. Mouithys-Mickalad, G. DebyDupont, P. Neven, and D. Serteyn, "Intra- and extracellular antioxidant capacities of the new water-soluble form of curcumin (NDS27) on stimulated neutrophils and HL-60 cells," Chemico-Biological Interactions, vol. 201, no. 1-3, pp. 49-57, 2013.

[30] J.-C. Wu, C.-S. Lai, V. Badmaev, K. Nagabhushanam, C.-T. Ho, and M.-H. Pan, "Tetrahydrocurcumin, a major metabolite of curcumin, induced autophagic cell death through coordinative modulation of PI3K/Akt-mTOR and MAPK signaling pathways in human leukemia HL-60 cells," Molecular Nutrition and Food Research, vol. 55, no. 11, pp. 1646-1654, 2011.

[31] T. Zhou, L. Ye, Y. Bai et al., "Autophagy and apoptosis in hepatocellular carcinoma induced by EF25-(GSH)2: a novel curcumin analog," PLoS ONE, vol. 9, Article ID e107876, 2014.

[32] C. Kantara, M. O'Connell, S. Sarkar, S. Moya, R. Ullrich, and P. Singh, "Curcumin promotes autophagic survival of a subset of colon cancer stem cells, which are ablated by DCLK1-siRNA," Cancer Research, vol. 74, no. 9, pp. 2487-2498, 2014.

[33] M. S. Charpentier, R. A. Whipple, M. I. Vitolo et al., "Curcumin targets breast cancer stem-like cells with microtentacles that persist in mammospheres and promote reattachment," Cancer Research, vol. 74, no. 4, pp. 1250-1260, 2014.

[34] P. Anand, C. Sundaram, S. Jhurani, A. B. Kunnumakkara, and B. B. Aggarwal, "Curcumin and cancer: an 'old-age' disease with an 'age-old' solution,' Cancer Letters, vol. 267, no. 1, pp. 133-164, 2008.

[35] J. Park, V. Ayyappan, E.-K. Bae et al., "Curcumin in combination with bortezomib synergistically induced apoptosis in human multiple myeloma U266 cells," Molecular Oncology, vol. 2, no. 4, pp. 317-326, 2008.

[36] Y. Yu, S. S. Kanwar, B. B. Patel, J. Nautiyal, F. H. Sarkar, and A. P. N. Majumdar, "Elimination of colon cancer stem-like cells by the combination of curcumin and FOLFOX," Translational Oncology, vol. 2, no. 4, pp. 321-328, 2009.
[37] K. Srimuangwong, C. Tocharus, J. Tocharus, A. Suksamrarn, and P. Y. Chintana, "Effects of hexahydrocurcumin in combination with 5-fuorouracil on dimethylhydrazine-induced colon cancer in rats," World Journal of Gastroenterology, vol. 18, no. 47, pp. 6951-6959, 2012.

[38] F. Faião-Flores, J. A. Q. Suarez, P. C. Pardi, and D. A. Maria, "DM-1, sodium 4-[5-(4-hydroxy-3-methoxyphenyl)-3oxo-penta-1,4-dienyl]-2-methoxy-phenolate: a curcumin ana$\log$ with a synergic effect in combination with paclitaxel in breast cancer treatment," Tumor Biology, vol. 33, no. 3, pp. 775$785,2012$.

[39] X.-Y. Zhang, Q.-X. Bai, G.-S. Huang, H. Zhao, J.-J. Chen, and L.-J. Yang, "Effect of curcumin in combination with bortezomib on proliferation and apoptosis of human multiple myeloma cell line H929 and its mechanism," Zhongguo Shi Yan Xue Ye Xue Za Zhi, vol. 19, no. 3, pp. 684-688, 2011.

[40] T. Nakane, H. Nakamae, H. Koh et al., "Reduced-intensity conditioning by fludarabine/busulfan without additional irradiation or T-cell depletion leads to low non-relapse mortality in unrelated bone marrow transplantation," International Journal of Hematology, vol. 93, no. 4, pp. 509-516, 2011.

[41] J.-Y. Wang, P. Yu, S. Chen et al., "Activation of Rac1 GTPase promotes leukemia cell chemotherapy resistance, quiescence and niche interaction," Molecular Oncology, vol. 7, no. 5, pp. 907916, 2013

[42] U. Testa, "Leukemia stem cells," Annals of Hematology, vol. 90, no. 3, pp. 245-271, 2011.

[43] M. Sehl, H. Zhou, J. S. Sinsheimer, and K. L. Lange, "Extinction models for cancer stem cell therapy," Mathematical Biosciences, vol. 234, no. 2, pp. 132-146, 2011.

[44] S. W. Lane, D. T. Scadden, and D. G. Gilliland, "The leukemic stem cell niche: current concepts and therapeutic opportunities," Blood, vol. 114, no. 6, pp. 1150-1157, 2009.

[45] E. C. Zeestraten, A. Benard, M. S. Reimers et al., "The prognostic value of the apoptosis pathway in colorectal cancer: a review of the literature on biomarkers identified by immunohistochemistry," Biomarkers in Cancer, vol. 5, pp. 13-29, 2013.

[46] B. P. Eckelman, G. S. Salvesen, and F. L. Scott, "Human inhibitor of apoptosis proteins: why XIAP is the black sheep of the family," EMBO Reports, vol. 7, no. 10, pp. 988-994, 2006.

[47] Y. E. Choi, M. Butterworth, S. Malladi, C. S. Duckett, G. M. Cohen, and S. B. Bratton, "The E3 ubiquitin ligase cIAP1 binds and ubiquitinates caspase- 3 and -7 via unique mechanisms at distinct steps in their processing," The Journal of Biological Chemistry, vol. 284, no. 19, pp. 12772-12782, 2009.

[48] A. M. Verhagen, J. Silke, P. G. Ekert et al., "HtrA2 promotes cell death through its serine protease activity and its ability to antagonize inhibitor of apoptosis proteins," The Journal of Biological Chemistry, vol. 277, no. 1, pp. 445-454, 2002.

[49] L. Miguel Martins, I. Iaccarino, T. Tenev et al., “The serine protease Omi/HtrA2 regulates apoptosis by binding XIAP through a Reaper-like motif," Journal of Biological Chemistry, vol. 277, no. 1, pp. 439-444, 2002.

[50] K. Sekine, Y. Hao, Y. Suzuki, R. Takahashi, T. Tsuruo, and M. Naito, "HtrA2 cleaves Apollon and induces cell death by IAP-binding motif in Apollon-deficient cells," Biochemical and Biophysical Research Communications, vol. 330, no. 1, pp. 279285, 2005.

[51] C. H. A. Cheung, C.-C. Huang, F.-Y. Tsai et al., "Survivinbiology and potential as a therapeutic target in oncology," OncoTargets and Therapy, vol. 6, pp. 1453-1462, 2013. 
[52] L. Bongiovanni, F. Di Diodoro, S. L. Della, and C. Brachelente, "On the role of survivin as a stem cell biomarker of canine hair follicle and related tumours," Veterinary Dermatology, vol. 25, no. 2, pp. 138-141, e39-e40, 2014.

[53] J. R. Kanwar, G. Mahidhara, K. Roy et al., "Fe-bLf nanoformulation targets survivin to kill colon cancer stem cells and maintains absorption of iron, calcium and zinc," Nanomedicine, vol. 10, no. 1, pp. 35-55, 2015.

[54] S. Fukuda, M. Abe, C. Onishi et al., "Survivin selectively modulates genes deregulated in human leukemia stem cells," Journal of Oncology, vol. 2011, Article ID 946936, 14 pages, 2011.

[55] R. Gedaly, R. Galuppo, M. F. Daily et al., "Targeting the Wnt/beta-catenin signaling pathway in liver cancer stem cells and hepatocellular carcinoma cell lines with FH535," PLoS ONE, vol. 9, no. 6, Article ID e99272, 2014.

[56] R. Galuppo, E. Maynard, M. Shah et al., "Synergistic inhibition of HCC and liver cancer stem cell proliferation by targeting RAS/RAF/MAPK and WNT/beta-catenin pathways," Anticancer Research, vol. 34, pp. 1709-1713, 2014. 

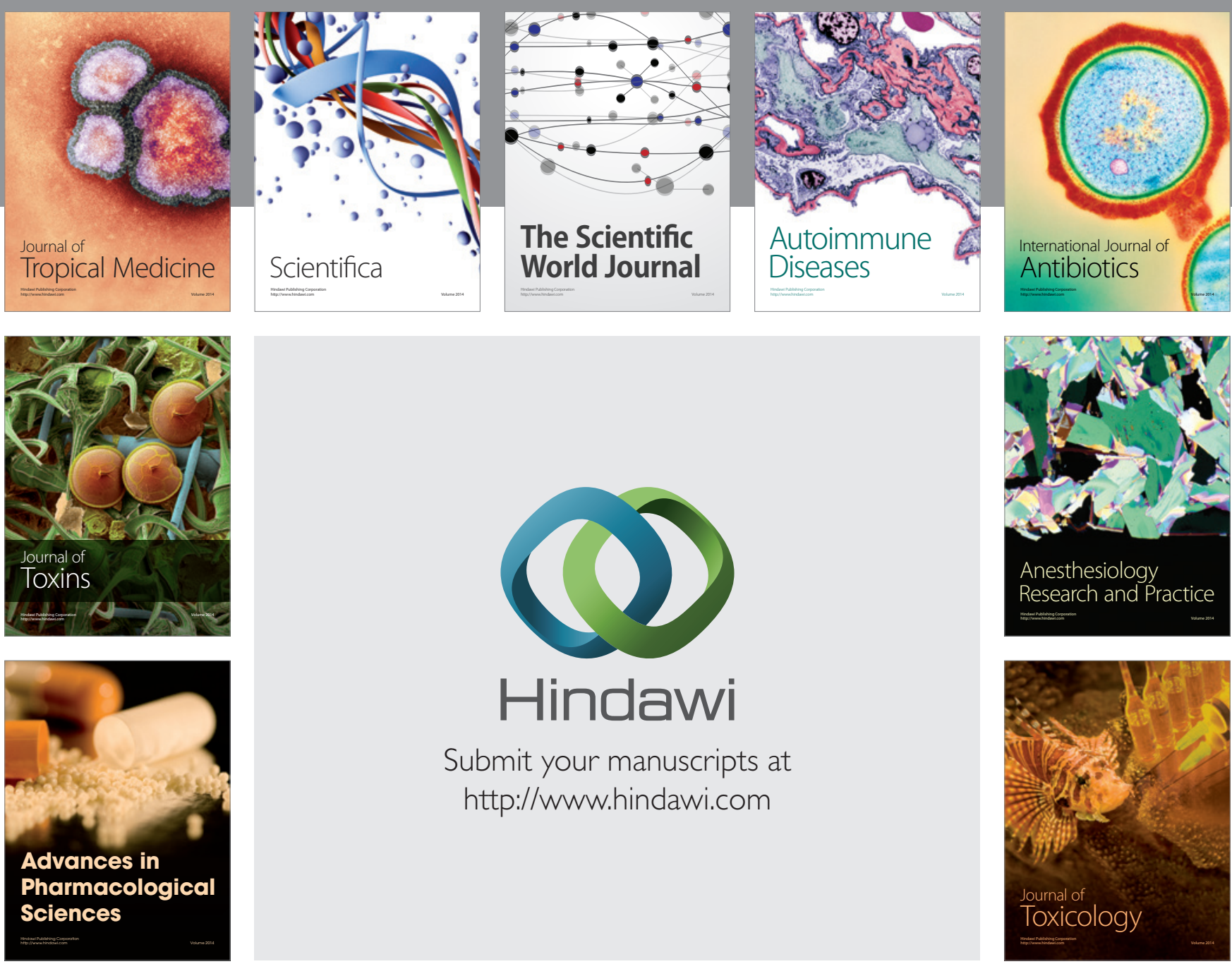

\section{Hindawi}

Submit your manuscripts at

http://www.hindawi.com
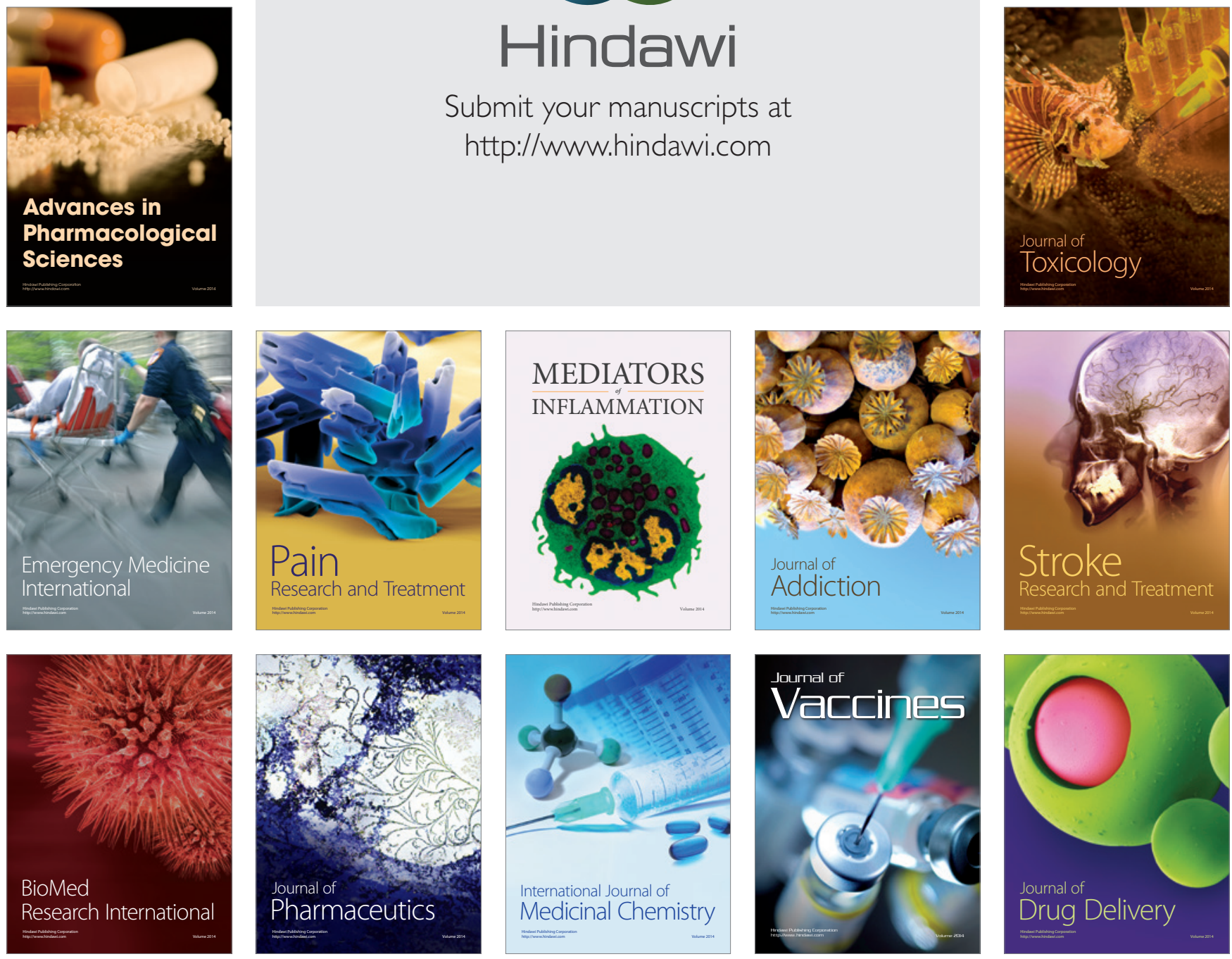